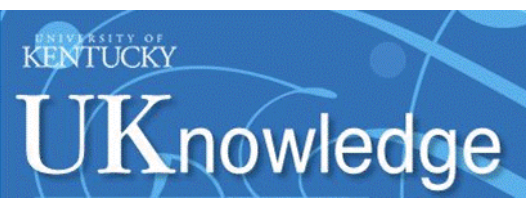

University of Kentucky

UKnowledge

$1-20-2022$

\title{
Transforming Obesity Prevention for CHILDren (TOPCHILD) \\ Collaboration: Protocol for a Systematic Review with Individual Participant Data Meta-Analysis of Behavioural Interventions for the Prevention of Early Childhood Obesity
}

Kylie E. Hunter

University of Sydney, Australia

Brittany J. Johnson

Flinders University, Australia

Lisa Askie

University of Sydney, Australia

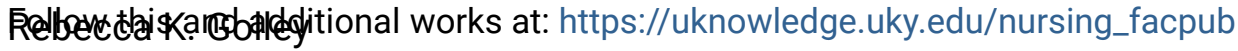

d'Pars University Australia the Eplemiology Commons, Nursing Commons, Pediatrics Commons, and the Preventive LodisènA.CBaunons

Ringhereltukf(Exofoed, Afretralliack form in a new tab to let us know how this document benefits you.

\section{Reposittorggeifationditional authors}

Hunter, Kylie E.; Johnson, Brittany J.; Askie, Lisa; Golley, Rebecca K.; Baur, Louise A.; Marschner, Ian C.; Taylor, Rachael W.; Wolfenden, Luke; Wood, Charles T.; Mihrshahi, Seema; Hayes, Alison J.; Rissel, Chris; Robledo, Kristy P.; O'Connor, Denise A.; Espinoza, David; Staub, Lukas P.; Chadwick, Paul; Taki, Sarah; Barba, Angie; Libesman, Sol; and Linares, Ana Maria, "Transforming Obesity Prevention for CHILDren (TOPCHILD) Collaboration: Protocol for a Systematic Review with Individual Participant Data MetaAnalysis of Behavioural Interventions for the Prevention of Early Childhood Obesity" (2022). Nursing Faculty Publications. 64.

https://uknowledge.uky.edu/nursing_facpub/64

This Article is brought to you for free and open access by the College of Nursing at UKnowledge. It has been accepted for inclusion in Nursing Faculty Publications by an authorized administrator of UKnowledge. For more information, please contact UKnowledge@lsv.uky.edu. 


\section{Transforming Obesity Prevention for CHILDren (TOPCHILD) Collaboration: Protocol for a Systematic Review with Individual Participant Data Meta-Analysis of Behavioural Interventions for the Prevention of Early Childhood Obesity}

Digital Object Identifier (DOI)

https://doi.org/10.1136/bmjopen-2020-048166

Notes/Citation Information

Published in BMJ Open, v. 12, issue 1, 048166.

(c) Author(s) (or their employer(s)) 2021

This is an open access article distributed in accordance with the Creative Commons Attribution Non Commercial (CC BY-NC 4.0) license, which permits others to distribute, remix, adapt, build upon this work non-commercially, and license their derivative works on different terms, provided the original work is properly cited, appropriate credit is given, any changes made indicated, and the use is non-commercial. See: https://creativecommons.org/licenses/by-nc/4.0/.

The first 20 authors and the author from the University of Kentucky are shown on the author list above. Please refer to the downloaded document for the complete author list.

Authors

Kylie E. Hunter, Brittany J. Johnson, Lisa Askie, Rebecca K. Golley, Louise A. Baur, lan C. Marschner, Rachael W. Taylor, Luke Wolfenden, Charles T. Wood, Seema Mihrshahi, Alison J. Hayes, Chris Rissel, Kristy P. Robledo, Denise A. O'Connor, David Espinoza, Lukas P. Staub, Paul Chadwick, Sarah Taki, Angie Barba, Sol Libesman, and Ana Maria Linares

This article is available at UKnowledge: https://uknowledge.uky.edu/nursing_facpub/64 


\section{BMJ Open}

Transforming Obesity Prevention for CHILDren (TOPCHILD) Collaboration: protocol for a systematic review with individual participant data metaanalysis of behavioural interventions for the prevention of early childhood obesity

To cite: Hunter KE, Johnson BJ, Askie L, et al. Transforming Obesity Prevention for CHILDren (TOPCHILD) Collaboration: protocol for a systematic review with individual participant data meta-analysis of behavioural interventions for the prevention of early childhood obesity. BMJ Open 2022;12:e048166. doi:10.1136/ bmjopen-2020-048166

- Prepublication history and additional supplemental material for this paper are available online. To view these files, please visit the journal online (http://dx.doi.org/10.1136/ bmjopen-2020-048166)

Received 18 December 2020 Accepted 18 November 2021

\section{Linked}

http://dx.doi.org/10.1136/ bmjopen-2020-048165

Check for updates

(C) Author(s) (or their employer(s)) 2021. Re-use permitted under CC BY-NC. No commercial re-use. See rights and permissions. Published by BMJ.

For numbered affiliations see end of article.

Correspondence to

Kylie E Hunter;

kylie.hunter@sydney.edu.au
Kylie E Hunter (D) ,' Brittany J Johnson (D) ,' Lisa Askie, ${ }^{1}$ Rebecca K Golley, ${ }^{2}$ Louise A Baur, ${ }^{3}$ Ian C Marschner, ${ }^{1}$ Rachael W Taylor, ${ }^{4}$ Luke Wolfenden, ${ }^{5}$ Charles T Wood, ${ }^{6}$ Seema Mihrshahi, ${ }^{7}$ Alison J Hayes, ${ }^{8}$ Chris Rissel, ${ }^{8}$ Kristy P Robledo, ${ }^{1}$ Denise A O'Connor (D) 9,10 David Espinoza, ${ }^{1}$ Lukas P Staub, ${ }^{1}$ Paul Chadwick, ${ }^{11}$ Sarah Taki, ${ }^{8,12}$ Angie Barba, ${ }^{1}$ Sol Libesman, ${ }^{1}$ Mason Aberoumand, ${ }^{1}$ Wendy A Smith, ${ }^{13,14}$ Michelle Sue-See, ${ }^{14}$ Kylie D Hesketh (D) , ${ }^{15}$ Jessica L Thomson, ${ }^{16}$ Maria Bryant, ${ }^{17}$ Ian M Paul, ${ }^{18}$ Vera Verbestel, ${ }^{19}$ Cathleen Odar Stough, ${ }^{20}$ Li Ming Wen, ${ }^{8,12}$ Junilla K Larsen, ${ }^{21}$ Sharleen L O'Reilly, ${ }^{22}$ Heather M Wasser, ${ }^{23}$ Jennifer S Savage, ${ }^{24}$ Ken K Ong, ${ }^{25}$ Sarah-Jeanne Salvy, ${ }^{26}$ Mary Jo Messito, ${ }^{27}$ Rachel S Gross, ${ }^{27}$ Levie T Karssen, ${ }^{21}$ Finn E Rasmussen, ${ }^{28}$ Karen Campbell, ${ }^{15}$ Ana Maria Linares, ${ }^{29}$

Nina Cecilie Øverby (D) , ${ }^{30}$ Cristina Palacios, ${ }^{31}$ Kaumudi J Joshipura, ${ }^{32,33}$ Carolina González Acero, ${ }^{34}$ Rajalakshmi Lakshman, ${ }^{25}$ Amanda L Thompson, ${ }^{23,35}$ Claudio Maffeis, ${ }^{36}$ Emily Oken, ${ }^{37}$ Ata Ghaderi, ${ }^{38}$ Maribel Campos Rivera, ${ }^{39}$ Ana B Pérez-Expósito, ${ }^{40}$ Jinan C Banna, ${ }^{41}$ Kayla de la Haye, ${ }^{42}$ Michael Goran, ${ }^{42}$ Margrethe Røed, ${ }^{30}$ Stephanie Anzman-Frasca, ${ }^{43}$ Barry J Taylor, ${ }^{44}$

Anna Lene Seidler (D) , ${ }^{1}$ on behalf of the Transforming Obesity Prevention for CHILDren (TOPCHILD) Collaboration

\section{ABSTRACT}

Introduction Behavioural interventions in early life appear to show some effect in reducing childhood overweight and obesity. However, uncertainty remains regarding their overall effectiveness, and whether effectiveness differs among key subgroups. These evidence gaps have prompted an increase in very early childhood obesity prevention trials worldwide. Combining the individual participant data (IPD) from these trials will enhance statistical power to determine overall effectiveness and enable examination of individual and trial-level subgroups. We present a protocol for a systematic review with IPD meta-analysis to evaluate the effectiveness of obesity prevention interventions commencing antenatally or in the first year after birth, and to explore whether there are differential effects among key subgroups.

Methods and analysis Systematic searches of Medline, Embase, Cochrane Central Register of Controlled Trials, Cumulative Index to Nursing and Allied Health Literature (CINAHL), Psyclnfo and trial registries for all ongoing and completed randomised controlled trials evaluating behavioural interventions for the prevention of early childhood obesity have been completed up to March 2021 and will be updated annually to include additional trials. Eligible trialists will be asked to share their IPD; if unavailable, aggregate data will be used where possible. An IPD meta-analysis and a nested prospective meta-analysis will be performed using methodologies recommended by the Cochrane Collaboration. The primary outcome will be body mass index z-score at age $24 \pm 6$ months using WHO Growth Standards, and effect differences will be explored among prespecified individual and trial-level subgroups. Secondary outcomes include other child weight-related measures, infant feeding, dietary intake, physical activity, sedentary behaviours, sleep, parenting measures and adverse events.

Ethics and dissemination Approved by The University of Sydney Human Research Ethics Committee (2020/273) and Flinders University Social and Behavioural Research Ethics Committee (HREC CIA2133-1). Results will be 


\section{Strengths and limitations of this study}

- This will be the largest individual participant data (IPD) metaanalysis evaluating behavioural interventions for the prevention of early childhood obesity to date, and will provide the most reliable and precise estimates of early intervention effects to inform future decision-making.

- IPD meta-analysis methodology will enable unprecedented exploration of important individual and trial-level characteristics that may be associated with childhood obesity or that may be effect modifiers.

- The proposed innovative methodologies are feasible and have been successfully piloted by members of our group.

- It may not be possible to obtain IPD from all eligible trials; in this instance, aggregate data will be used where available, and sensitivity analyses will be conducted to assess inclusion bias.

- Outcome measures may be collected and reported differently across included trials, potentially increasing imprecision; however, we will harmonise available data where possible, and encourage those planning or conducting ongoing trials to collect common core outcomes following prospective meta-analysis methodology.

relevant to clinicians, child health services, researchers, policy-makers and families, and will be disseminated via publications, presentations and media releases.

PROSPERO registration number CRD42020177408.

\section{INTRODUCTION}

Childhood obesity is one of the most serious public health issues of the 21st century, and requires urgent action. ${ }^{12}$ Globally, an estimated 38 million $(6 \%)$ children aged under 5 years were living with overweight or obesity in $2019,{ }^{3}$ and prevalence is increasing across every continent as environments become more obesity conducive. ${ }^{45}$ While childhood obesity affects all sections of society, it disproportionately affects racial and ethnic minority groups $^{67}$ and populations with a lower socioeconomic position (SEP), and thus is also a major health equity issue. ${ }^{4}$ Children with obesity are much more likely to have obesity across the lifecourse, ${ }^{89}$ and are at increased risk of short-term and long-term negative health sequelae, such as poor mental and musculoskeletal health, type 2 diabetes, asthma and cardiovascular disease. ${ }^{10}{ }^{11}$ This places a large burden on healthcare systems, ${ }^{12}$ and has significant economic consequences arising from increased disability and decreased productivity and life expectancy. ${ }^{13}$ Thus, identifying modifiable behaviours for the early prevention of childhood obesity is critical to inform the development of early intervention strategies.

There are a variety of modifiable behaviours that may influence energy balance and therefore may be implicated in childhood obesity prevention, namely, feeding practices, dietary intake, physical activity, sedentary behaviours and sleep. For instance, appropriate responsive feeding has been identified as promising for obesity prevention, ${ }^{14-16}$ while consumption of sugar-sweetened beverages is associated with severe obesity in children aged less than 5 years. ${ }^{17}$ Data are mixed on the protective benefits of breast feeding for the prevention of obesity, though some studies suggest that longer duration of exclusive breast feeding may provide modest protection. ${ }^{18-23}$ Similarly, there may be an association between age at introduction of solids and growth, ${ }^{24}$ with mixed results surrounding the direction of this association and the underlying causal mechanisms. Previous systematic reviews have reported significant inverse associations between physical activity and measures of adiposity in children. ${ }^{25-27}$ Conversely, sedentary behaviours such as television viewing or screen time are associated with higher body mass index (BMI) levels ${ }^{28}$ and greater adiposity ${ }^{30}$ in young children. There is now also a large body of observational evidence supporting the relationship between short sleep duration and an increased risk of obesity across all age groups, including infants and young children, ${ }^{31-35}$ though a recent systematic review found inconsistent evidence of an association between longer infant sleep duration and healthier body composition up to age 24 months. ${ }^{36}$

In addition to these behaviours, individual-level covariates known or hypothesised to be predictive for childhood obesity include prepregnancy maternal and paternal BMI, age, race, ethnicity, SEP, excess gestational weight gain, parity, smoking during pregnancy, gestational diabetes, birth mode of delivery (caesarean, vaginal), birth weight, gestational age at birth, baby's sex, intrapartum antibiotic prophylaxis and childcare attendance. ${ }^{67223738}$ Some of these covariates may also be individual-level effect modifiers, prediciting how effective an intervention is likely to be, for example, SEP and race/ethnicity. Trial-level characteristics such as timing of intervention onset, setting and the level of well-child healthcare available in the community may also modify intervention effectiveness. ${ }^{39}$

\section{Limitations and evidence gaps identified in previous reviews}

In the past 5 years, there have been numerous reviews of childhood obesity prevention trials encompassing a variety of intervention types, settings and age groups. ${ }^{140-46} \mathrm{Few}$ of these focused solely on infancy, and many spanned multiple life stages from the prenatal period to 18 years of age. One review found that family-based childhood obesity prevention interventions most frequently targeted children 2-10 years of age $(78 \%)$, with fewer targeting infants aged $0-1$ year (24\%) or the prenatal period $(8 \%) .{ }^{40}$ Most reviews highlighted the urgent need for further rigorous evidence to inform obesity prevention interventions in the very early childhood years. ${ }^{14} 40-4446$ Given the consequences of rapid early life weight gain, associated epigenetic changes and early onset of obesity in many children, ${ }^{347} 48$ there is strong rationale to start preventive interventions early when biology is most amenable to change, and before negative obesityconducive behavioural patterns are established. ${ }^{2}$

Most of the childhood obesity prevention reviews to date have used qualitative methodology such as narrative reviews, content analysis and systematic reviews without meta-analysis to describe variations in study design, setting, population, interventions and outcomes, and to 
hypothesise that certain individual and trial-level characteristics may enhance effectiveness via proposed conceptual frameworks and intervention models. ${ }^{14} 4042-46$ Yet, quantitative evaluation is required to formally test these hypotheses. Recently, Brown et $a t^{41}$ updated a Cochrane systematic review and aggregate data meta-analysis on obesity prevention in children aged 0-18 years, and found that interventions focusing on diet and physical activity combined can lead to a small reduction in BMI z-score in children aged $0-5$ years of age (mean difference $-0.07,95 \%$ CI -0.14 to -0.01$)$. However, a huge variety in intervention approaches limited their ability to conduct meaningful comparisons, and many multicomponent interventions were originally reported as a whole package, precluding evaluation of discrete intervention characteristics. Moreover, the aggregated data were insufficient to derive conclusions on effect differences by individual-level characteristics such as ethnicity and SEP.

The Early Prevention of Obesity in Children (EPOCH) Collaboration conducted a world-first individual participant data (IPD) prospective meta-analysis (PMA) of four randomised controlled trials (RCTs) of behavioural interventions for the prevention of early childhood obesity. ${ }^{39}$ They found that, compared with usual care, early childhood interventions were modestly effective in reducing BMI z-score 18-24 months after birth by 0.12 SD (which translates to a $2 \%$ decrease in obesity prevalence). However, when accounting for missing data this difference was no longer significant. There was some heterogeneity across trials, and interventions appeared to be more effective in populations with limited publicly funded existing healthcare programmes, in this instance defined as a maximum of one postnatal home visit. ${ }^{39}$ However, this finding needs to be confirmed in analyses including more than four studies. EPOCH's predictive analyses of individual and trial-level factors did not have sufficient power to detect reliable differences in BMI z-score. Thus, the overall effectiveness of early obesity prevention interventions remains uncertain, as does whether there may be differential effects among subgroups.

\section{Need for IPD meta-analysis}

The limitations and evidence gaps described above highlight the need for more powerful and in-depth analyses focusing on preventive interventions in very early childhood. Since the EPOCH PMA, ${ }^{39}$ we have identified more than 60 additional ongoing or completed very early obesity prevention trials worldwide with a combined sample size of more than 50000 participants. While most trials are powered to detect some important differences in key outcomes, individually they have limited power to detect a difference in our primary outcome, BMI z-score at $24 \pm 6$ months of age. In order to reliably detect a reduction in BMI z-score similar to that seen in EPOCH $(-0.12),{ }^{39} 2920$ participants are required (90\% power, 2-sided 5\% level of significance). Moreover, usually about four times that sample size $(\mathrm{n}$ 12 000) is required to detect differences in subgroups. ${ }^{49}$ The expected total sample size for Transforming Obesity Prevention for CHILDren (TOPCHILD) will exceed these estimates (as by July 2021, 45 trials including 40030 eligible participants have already agreed to share their IPD).

Conducting a trial of this size would be time and resource intensive. A more efficient method is to combine IPD from trials in a pooled analysis to increase the sample size and therefore statistical power. This strengthens the chance of detecting intervention effect differences, and enables us to determine the size of such effects with greater certainty, ${ }^{50}$ while also allowing variation in study designs and population which heightens generalisability and allows a greater diversity to study effect modification for different subgroups of individuals or trial characteristics. ${ }^{51}$ Moreover, this collaborative approach maximises the use of existing data, thereby reducing research waste.

Thus, we will conduct an IPD meta-analysis with detailed subgroup analyses of all available trials to confirm whether early obesity prevention interventions commencing antenatally or in the first year after birth are effective, and whether effectiveness varies across subgroups defined by individual-level or trial-level characteristics. The knowledge generated from this study can be used to inform decision-making around the design and implementation of more effective, efficient, equitable and targeted interventions for the prevention of childhood obesity and its sequelae.

\section{Objectives}

This IPD meta-analysis will address the following research questions:

1. Compared with usual care, no intervention or attentional control, what are the effects of parent/caregiverfocused behavioural obesity prevention interventions commencing during pregnancy or infancy on:

a. child BMI z-score at age 24 months ( \pm 6 months)? (primary outcome),

b. child BMI z-score at alternative timepoints, other child weight-related measures, infant feeding, dietary intake, physical activity, sedentary behaviours, sleep, parenting measures and adverse events? (secondary outcomes),

2. Do intervention effects vary across individual-level characteristics (eg, parental BMI, parity, SEP, birth weight)?

3. Do intervention effects vary across trial-level characteristics (eg, access to existing well-child healthcare programmes, intervention mode of delivery, timing of intervention onset)?

\section{METHODS AND ANALYSIS}

We will conduct a systematic review with IPD meta-analysis and a nested PMA according to the methods recommended by the Cochrane Collaboration. ${ }^{52}{ }^{53}$ A nested PMA enables integration of prospective evidence into a retrospective meta-analysis, and harmonisation among planned/ongoing studies. ${ }^{53}$ Lead investigators of eligible 
trials will be invited to share their IPD and join the TOPCHILD Collaboration (www.topchildcollaboration. org). This protocol adheres to the Preferred Reporting Items for Systematic Review and Meta-Analysis Protocols ${ }^{54}$ (online supplemental appendix 1).

\section{Eligibility criteria}

Types of studies

This systematic review will include RCTs only, including feasibility studies, pilot trials and definitive trials. Randomisation may occur at the individual level or by cluster (eg, child care, community), including stepped-wedge designs. Quasi-randomised trials are excluded as they may introduce bias. There are no language or date restrictions.

\section{Trial participants}

Participants will be parents/caregivers (including pregnant women) and their infant(s) aged 0-12 months (at baseline). Caregiver is defined as the person with primary responsibility for care of the child, and excludes secondary sources of support, such as child care providers and early childhood teachers. Women may be primipara or multipara, and both singletons and multiples are eligible.

\section{Types of interventions}

Interventions must be behavioural interventions targeting parents/caregivers, and include at least one component related to modifiable child behaviours that may influence overweight/obesity risk (eg, infant feeding, dietary intake, physical activity, sedentary behaviours, sleep). They may commence in the preconception or antenatal phase but must include intervention exposure targeting the birth to 12 months infancy stage, as pregnancy-only interventions are considered distinct and are currently being examined by Dodd et al in a separate IPD meta-analysis. ${ }^{55}$ Only childhood obesity prevention-focused trials will be included; these are defined as trials that clearly state childhood obesity prevention as a key aim/objective. Interventions focused only on improving an obesity-related behaviour (eg, sleep, delayed introduction of solid foods), as well as those focused on treatment of obesity, stunting or underweight will be excluded. Trials with a dual focus to prevent obesity and undernutrition are eligible, though we will carefully consider and prespecify how their data will be incorporated in the statistical analysis plan. Interventions focused solely on nutritional supplements will be excluded, as they are not considered to be behavioural interventions.

\section{Types of comparator/control}

Eligible trials must have either (1) a usual care control arm, defined as existing local child healthcare, or (2) no intervention (including waitlist control) or (3) attention control (eg, child safety education).

Types of outcome measures

To be included, trials must collect at least one of the child weight-related outcomes listed in table 1 post intervention (at any age), that is, BMI/BMI z-score, prevalence of overweight/obesity, per cent fat content/adiposity, skinfold thickness, abdominal circumference, waist-to-height ratio. This is considered a legitimate and pragmatic approach given our review is of multicomponent public health interventions focusing on obesity. ${ }^{56}$

\section{Eligibility for nested PMA}

In accordance with PMA methodology, ${ }^{53}$ only planned/ ongoing trials will be eligible for the nested PMA if trial results were not yet known to the investigator/s at the time the main components of the TOPCHILD protocol (ie, aims and objectives, hypotheses, eligibility criteria, main outcomes, subgroup and sensitivity analyses) were initially agreed in December 2020. We encourage investigators of planned/ongoing studies to collect the outcomes and subgroup variables listed in table 1 where possible, to facilitate data harmonisation and synthesis.

\section{Information sources and search strategy}

In March 2020, we undertook an initial systematic search for eligible trials using the following databases from their inception: Medline (Ovid), Embase (Ovid), Cochrane Central Register of Controlled Trials, CINAHL (EBSCO), PsycInfo, ClinicalTrials.gov and the WHO's International Clinical Trials Registry Platform's Search Portal. The full search strategy is available in online supplemental appendix 2. This search will be updated annually for the duration of the TOPCHILD Collaboration (currently funded until end 2023). Collaborators and contacts will also be asked to notify us of any planned, ongoing or completed trials of which they are aware that may meet the eligibility criteria.

\section{Selection of studies for inclusion in the review}

Two members of the TOPCHILD Steering Group will independently screen all retrieved records against eligibility criteria. Any discrepancies will be resolved by discussion or, if required, adjudication by a third reviewer from the Steering Group. The Principal Investigator and/or corresponding author of eligible trials will be invited by email to join the TOPCHILD Collaboration. If there is no response to initial emails and reminders, we will contact co-authors and/or other contacts listed in registration records and consult our existing networks to see if they can reach out to those they may know. If IPD cannot be obtained for an eligible trial, we will use aggregate data sourced from publications where available.

Online supplemental appendix 3 lists eligible trials identified up to March 2021.

\section{Data collection, management and confidentiality \\ Data receipt/extraction}

Trialists of all eligible studies will be invited to share deidentified IPD via secure data transfer platforms or via an institutional-secure email using password-protected zip files. Data will be provided according to a prespecified coding template where possible. Otherwise, data will be accepted in any format and recoded as necessary. The 
Table 1 Outcomes and subgroups

Variable Definition/explanatory text/examples*

Primary outcome

BMl z-score at age 24 months $\left( \pm 6 \quad\right.$ Determined in accordance with WHO growth standards ${ }^{60}$ months)

Secondary outcomes

BMI z-score at 12 months ( \pm 3 months) Determined in accordance with WHO growth standards ${ }^{60}$

BMl z-score at 48 months ( \pm 12 months) Determined in accordance with WHO growth standards ${ }^{60}$

BMI z-score beyond 60 months

Determined in accordance with WHO growth standards ${ }^{60}$

Other weight-related measures

For example, prevalence of overweight/obesity (defined as BMI z-score of at least 2 SD above the WHO reference), per cent fat content/ adiposity, skinfold thickness, abdominal circumference, waist-to-height ratio, velocity of weight gain, weight-forlength, per cent excess BMI >95th percentile, adiposity rebound

Infant feeding

For example, breast feeding initiation and duration, exclusivity of breast feeding, age at introduction of solid foods (complementary feeding)

Dietary intake

For example, energy intake, intake of fruit, vegetables, energy dense nutrient poor foods, and sugar-sweetened beverages

Sedentary behaviours

For example, screen time, restrained time while awake (in prams/strollers, highchairs, strapped on a caregiver's back or chest)

Physical activity

For example, active play duration, prone play ('tummy time'), device assessed physical activity time

Sleep

For example, sleep duration, measures of sleep quality such as frequency and duration of waking at night

Parental/caregiver measures

General and domain-specific parenting styles and practices, for example, parenting self-efficacy, parenting styles, parent feeding practices, parent physical activity practices, parent sleep practices, stress

Adverse events

For example, underweight, injuries, infection

Individual-level subgroups

Socioeconomic position

For example, household income/country median household income, parent/ caregiver highest education level, employment status

Parental weight status

Race/ethnicity

For example, maternal prepregnancy BMI, paternal BMI

Maternal age

Trialist defined

Maternal gestational weight gain

At recruitment

Parity

In kilograms

Mode of delivery at birth

Primipara, multiparous

Birth weight

Caesarean, vaginal

Weight for gestational age In grams

Sex

Small for gestational age, appropriate for gestational age, large for gestational age Female, male, uncertain/other

Gestational age at birth

Preterm, term

Household composition

For example, 2 versus 1 adult household, siblings, marital status

Type of pregnancy

Singleton, multiple

Maternal diabetes

Gestational, type 1, type 2

Smoking during pregnancy

yes/no

Infant's age at enrolment

In months

Child's age at final assessment

In months

Child care attendance

yes/no

Trial-level subgroups

Delivery mode (intervention)

Intervention setting

For example, face-to-face, letter, mobile digital device, individual versus group

For example, household residence, community healthcare facility

Continued 
Table 1 Continued

\begin{tabular}{ll}
\hline Variable & Definition/explanatory text/examples* \\
\hline Intervention dose/intensity & For example, total number of contacts, frequency of contact, duration of contact \\
\hline Fidelity & Planned, actual \\
\hline Timing of intervention onset & Preconception, antenatal, postnatal \\
\hline Timing of intervention completion & Child age in months \\
$\begin{array}{l}\text { Current level of background care in the } \\
\text { community }\end{array}$ & $\begin{array}{l}\text { Descriptive, categorisation to be determined, for example, expected number } \\
\text { of health contacts between birth and 1 year, expectation of attending prenatal } \\
\text { programmes (yes/no), etc. }\end{array}$ \\
Country & $\begin{array}{l}\text { Low, middle, high income } \\
\text { Behavioural } \pm \text { other intervention type }\end{array}$ \\
$\begin{array}{l}\text { Behavioural intervention(s) alone versus behavioural+other intervention type (eg, } \\
\text { supplement) }\end{array}$ \\
\hline
\end{tabular}

*Exact measures and definitions will depend on what the individual trials have collected and the degree to which harmonisation is possible. Specific details of all outcome measures will be elaborated on in our forthcoming statistical analysis plan, which will be agreed and signed off by the Collaboration before any data are analysed.

BMI, body mass index.

data management team (within the TOPCHILD Steering Group) will receive and store the data in perpetuity in a secure, customised database at the NHMRC Clinical Trials Centre, University of Sydney, and data management will follow the University of Sydney Data Management Policy 2014. Each trial will also be asked to provide metadata (ie, data that provides information about their trial dataset), such as questionnaires, data collection forms and data dictionaries to aid understanding of the dataset. Trial-level data, such as setting, intervention timing, mode of delivery, comparator/control details, method of sequence generation, allocation concealment, geographical location, sample size, outcome measures and definitions will be extracted into a database and cross-checked against any published reports, trial protocols, registration records and data collection sheets.

\section{Data processing}

Data from each trial will be checked with respect to range, internal consistency, consistency with published reports and missing items. Integrity of the randomisation process will be examined by reviewing the chronological randomisation sequence and pattern of assignment, as well as the balance of participant characteristics across intervention and control groups. Any inconsistencies or missing data will be discussed with trialists and/or data managers and resolved by consensus. Once finalised, data from each of the trials will be combined into a single TOPCHILD Collaboration database.

\section{Risk of bias assessment and certainty of evidence appraisal}

Included studies will be assessed for risk of bias by two independent reviewers from the TOPCHILD Steering Group using Version 2 of the Cochrane risk-of-bias tool for randomised trials (RoB 2) ${ }^{57}$ This tool includes five domains encompassing bias arising from: the randomisation process, deviations from intended interventions, missing outcome data, measurement of the outcome and selection of the reported result. For cluster-randomised trials, bias arising from identification or recruitment of individual participants within clusters will also be assessed. ${ }^{45}$ The certainty of evidence will be assessed according to Cochrane procedures ${ }^{58}$ using the Grading of Recommendations Assessment, Development and Evaluation approach. ${ }^{59}$ Any differences will be resolved by consensus or with a third reviewer from the TOPCHILD Steering Group.

\section{Primary outcome}

The primary outcome will be BMI z-score at age 24 months $( \pm 6$ months), determined in accordance with WHO growth standards. ${ }^{60}$ We selected BMI z-score, over other measures such as weight-for-length, in light of accumulating evidence that it is more highly correlated with weight status in infancy and is better at predicting future obesity risk. ${ }^{61-65}$ In addition, WHO BMI for age charts are applicable to all infants/children regardless of SEP or ethnicity, which aligns with the global nature of the TOPCHILD Collaboration. ${ }^{66}$

\section{Secondary outcomes}

All outcomes are detailed in table 1 . Where possible, definitions will be standardised, otherwise outcomes will be used as defined within each trial. Secondary outcomes include BMI z-score at other timepoints, other measures of child weight, infant feeding (including breast feeding and introduction of solid foods), dietary intake, sedentary behaviours, physical activity and sleep, as well as parent/ caregiver-related measures. We will also assess any adverse events, such as underweight or poor weight gain.

\section{Subgroups}

All included subgroups are listed in table 1. Individuallevel and trial-level subgroup analyses will be conducted for the primary outcome of BMI z-score at age 24 months ( \pm 6 months). Those of primary interest at the individual level include SEP, race/ethnicity, prepregnancy maternal/ paternal BMI, maternal age, gestational weight gain and 
parity, and at the trial level include timing of intervention onset, current level of background care in the community, recruitment country and mode of delivery.

Where possible, outcomes and subgroups will be collected as continuous variables to maximise power to detect intervention effects and interactions, and enable exploration of any non-linear relationships. ${ }^{67}$ Dichotomous and categorical variables will also be collected to aid interpretation, and if data are insufficient for the prespecified subgroup analyses, categories will be collapsed prior to any analyses being conducted.

\section{Data analysis}

A detailed statistical analysis plan will be prepared and agreed on by the TOPCHILD Collaboration members prior to any analyses being undertaken. Analyses will follow the intention-to-treat principle and include all randomised infant-parent/caregiver dyads for which data are available (including any that were excluded from the original study analysis). For cluster RCTs, correlated data will be taken into account by fitting the models using generalised estimating equations to derive appropriate standard errors. Correlations between multiples also will be accounted for in the analyses.

The primary analysis for all outcomes will be conducted using a one-stage approach combining all available IPD and aggregate data (where IPD are unavailable) to reduce the risk of availability bias. ${ }^{68} 69$ The combined dataset will be analysed including trial as a random effect. Models will be chosen appropriate to the outcome type. Generalised linear models with appropriate distributions and link functions will be used for continuous and binary outcomes, while Cox proportional hazards regression will be used to analyse time-to-event outcomes subject to censoring. For example, linear models will be used for the primary outcome while relative risk binomial regression with $\log$ link function will be used for prevalence of overweight/obesity, and Cox models will be used for breast feeding duration. Where possible, continuous outcomes and subgroup variables will be analysed on their continuous scale to maximise utility of available data. ${ }^{67}$

Heterogeneity of intervention effects across trials will be investigated using quantitative measures $\left(\mathrm{I}^{2}\right)$ supplemented by graphical presentations as recommended in the Cochrane Handbook. ${ }^{70}$ Any notable heterogeneity identified will be explored further to ascertain if the combination of trials is appropriate.

Results will be reported using appropriate estimates of intervention effect (relative risks, mean differences or hazard ratios) with $95 \%$ CIs and associated two-sided $\mathrm{p}$ values. For trials with multiple intervention arms, we will present the data for each intervention arm compared with the control arm, with the number of participants in the control arm adjusted to ensure no double counting. ${ }^{41}$ Missing data will be explored in sensitivity analyses using appropriate methods. All analyses will be performed using the open-source software $\mathrm{R}^{71}$
Differences in intervention effect between the prespecified subgroups will be examined by testing a treatment by subgroup interaction term within the 1-stage-model. Findings of subgroup analyses will be reported as exploratory ${ }^{72}$ and summarised using a 1-stage-approach supplemented by graphical presentation in a forest plot using a 2-stage-approach. Non-linear relationships will be explored for continuous subgroup variables using a multivariate meta-analysis of the trend. ${ }^{67}$

Other exploratory analyses for the primary outcome will include graphical presentation of BMI z-score distributions to investigate any differences beyond mean differences and examine any non-linear relationships. The potential for mediation and moderator analyses using parent/caregiver measures will be explored and detailed in a statistical analysis plan after we have extracted information about relevant variables collected by included trials.

\section{Assessment of selection or publication bias}

Potential selection bias and publication bias will be investigated by conducting a nested PMA and comparing prospectively versus retrospectively included trials in a sensitivity analysis. ${ }^{53}$ We will also seek to include any unreported outcomes sourced from each trial's IPD, which may alleviate selective outcome reporting bias. ${ }^{52}$ Lastly, contour-enhanced funnel plots will be used to examine whether there are differences in results between more and less precise studies.

\section{Adjustments for multiple testing}

Only one primary outcome was selected for this study (table 1). For secondary outcomes and subgroup analyses, no formal adjustments will be made for the potential inflation of type 1 error rates due to multiple testing. Instead, we will follow Schulz and Grimes' approach ${ }^{54}$ and recommendations of the Cochrane Collaboration. ${ }^{70}$ This involves cautious interpretation of the magnitudes of effect, patterns and consistency of results across related outcomes and clinical/biological plausibility rather than focusing on any single statistically significant result in isolation which can be extremely misleading. ${ }^{70} 72$

\section{Planned sensitivity analyses}

Where possible, the following sensitivity analyses will be conducted for the primary outcome:

- Two stage approach.

- Including IPD only, that is, excluding trials without IPD available..$^{55}$

- Including prospectively included trials only (nested PMA), that is, planned/ongoing trials for which results were not yet known to investigator/s at the time the main components of the TOPCHILD protocol were agreed. $^{53}$

- Adjusting for birth weight as a covariate.

- Excluding trials with a high risk of bias for sequence generation and/or allocation concealment and/or loss to follow-up. 
- Excluding trials with a significant conflict of interest (eg, funded by industry).

- The impact of missing data on conclusions about the intervention effect (if appropriate).

\section{Project management}

Membership of the TOPCHILD Collaboration includes trial representatives from each of the trials contributing IPD to the project, a Steering Group and an Advisory Group. Trial representatives have the opportunity to contribute their expert knowledge to the TOPCHILD Collaboration and provide input into the protocols, statistical analysis plan and final results manuscript. The Steering Group will be responsible for data collection, management and analysis, as well as communication within the Collaboration, including newsletter updates, maintenance of the TOPCHILD website and organisation of virtual or face-to-face collaborator meetings. The Advisory Group will comprise invited experts in childhood obesity prevention, IPD meta-analysis, statistics, behaviour change theory/methods and policy implementation.

\section{ETHICS AND DISSEMINATION \\ Ethical considerations}

IPD will be provided by each included trial on the stipulation that ethical approval has been provided by their respective Human Research Ethics Committees (or equivalent), and participants gave informed consent before enrolment to participate in the initial individual trials. Trialists remain the custodians of their own data, which will be deidentified before being shared with the TOPCHILD Collaboration. Ethical approval for this project has been granted by The University of Sydney Human Research Ethics Committee (2020/273) and Flinders University Social and Behavioural Research Ethics Committee (project no. HREC CIA2133-1).

\section{Publication policy}

TOPCHILD manuscripts will be prepared by the Steering Group in consultation with the Advisory Group, and circulated to the full Collaboration for comment, revision and approval prior to submission for publication. Any reports of the results of this study will be published either in the name of the collaborative group, or by representatives of the collaborative group on behalf of the TOPCHILD Collaboration, as agreed by members of the collaborative group.

\section{DISCUSSION}

This will be the largest IPD meta-analysis to date of trials evaluating behavioural obesity prevention interventions commencing in very early childhood. The findings will inform next generation obesity prevention initiatives that are effective, efficient and equitable. Such interventions could set children on a better health trajectory early on and reduce the potentially life-long burden of disease associated with obesity.

The main strengths of this study arise from use of IPD meta-analysis methodology, which is considered the 'gold standard'. ${ }^{73}$ It involves collecting the raw line-by-line data for each participant in each study from the original trialists. This can improve the quality of data, and enables more in-depth and precise analyses than would be possible using only published aggregate data. ${ }^{52}$ In particular, IPD meta-analysis will enable thorough exploration of individual-level and trial-level subgroups, so that we may quantify any differential effects and uncover the key determinants of successful outcomes. This addresses the limitations identified in previous reviews of childhood obesity prevention, ${ }^{39} 4146$ where such detailed and sufficiently powered analyses were simply not possible.

A potential limitation of this study is the risk of not obtaining IPD from all eligible studies, resulting in inclusion bias. Where available, we will include aggregate data from these studies, and conduct sensitivity analyses with inclusion of IPD only to explore potential bias. ${ }^{74}$ Further, there may be variations across studies in how measures are collected and reported, which may lead to some imprecision and difficulties pooling the data. We will seek to address this using nested PMA methodology, whereby researchers of planned or ongoing trials are encouraged to harmonise their trial design and collect core outcome measures to facilitate meta-analysis and interpretation. ${ }^{53}$ For completed studies, we will derive common outcome variables by cleaning, recoding and converting existing measures where possible.

We plan to complete the first round of study identification and IPD collection by early 2021, then conduct the primary analyses and disseminate the results by the end of 2022. Trials that are not completed in time to provide data for this cycle will remain a part of the TOPCHILD Collaboration, and their data will be included in future updates of TOPCHILD. Depending on data availability, we may consider collecting additional emerging variables of interest, such as intrapartum antibiotic prophylaxis and the microbiome, for future TOPCHILD cycles.

This IPD meta-analysis will be conducted in parallel with a complementary TOPCHILD project (Johnson et $a l^{75}$ unpublished), which aims to deconstruct childhood obesity interventions into their components (ie, delivery features, target behaviours and behaviour change techniques) using systematic, internationally recognised frameworks and both published and unpublished trial materials. In future, the resulting dataset curated from these two projects will be used for predictive modelling of intervention component effectiveness at an individual participant level, facilitating a personalised or precision medicine approach to public health prevention.

The TOPCHILD Collaboration will maximise use of existing trial data that will enable us to understand and use the most effective intervention components for specific population groups and contexts. It will provide urgently needed evidence to inform development and 
implementation of effective, efficient and equitable interventions for the prevention of early childhood obesity. The results will be of prime importance for guideline developers, policy-makers, consumers and the research community. Further information and updates on the TOPCHILD Collaboration can be found at www.topchild collaboration.org

\section{Author affiliations}

${ }^{1}$ NHMRC Clinical Trials Centre, The University of Sydney, Sydney, New South Wales, Australia

${ }^{2}$ Caring Futures Institute, College of Nursing and Health Sciences, Flinders University, Adelaide, South Australia, Australia

${ }^{3}$ Children's Hospital Westmead Clinical School, The University of Sydney, Westmead, New South Wales, Australia

${ }^{4}$ Department of Medicine, University of Otago, Dunedin, New Zealand

${ }^{5}$ School of Medicine and Public Health, The University of Newcastle, Callaghan, New South Wales, Australia

${ }^{6}$ School of Medicine, Duke University, Durham, North Carolina, USA

${ }^{7}$ Department of Health Systems and Populations, Faculty of Medicine, Health and Human Sciences, Macquarie University, Sydney, New South Wales, Australia

${ }^{8}$ School of Public Health, Faculty of Medicine and Health, The University of Sydney,

Sydney, New South Wales, Australia

${ }^{9}$ Department of Epidemiology and Preventive Medicine, School of Public Health and Preventive Medicine, Monash University, Clayton, Victoria, Australia

${ }^{10}$ Monash Department of Clinical Epidemiology, Cabrini Institute, Malvern, Victoria, Australia

${ }^{11}$ Centre For Behaviour Change, University College London, London, UK

${ }^{12}$ Population Health Research and Evaluation Hub, Sydney Local Health District, Camperdown, New South Wales, Australia

${ }^{13}$ Canterbury Community Health Centre, Sydney Local Health District, Campsie, New South Wales, Australia

${ }^{14}$ Consumer Representative, Sydney, New South Wales, Australia

${ }^{15}$ Institute for Physical Activity and Nutrition, Deakin University, Geelong, Victoria, Australia

${ }^{16}$ Agricultural Research Service, USDA, Stoneville, Mississippi, USA

${ }^{17}$ Department of Health Sciences and the Hull York Medical School, University of

York, York, UK

${ }^{18}$ Penn State College of Medicine, Hershey, Pennsylvania, USA

${ }^{19}$ Department of Rehabilitation Sciences, Ghent University, Ghent, Belgium

${ }^{20}$ Department of Psychology, University of Cincinnati, Cincinnati, Ohio, USA

${ }^{21}$ Behavioural Science Institute, Radboud Universiteit, Nijmegen, The Netherlands

${ }^{22}$ School of Agriculture and Food Science, University College Dublin, Dublin, Ireland

${ }^{23}$ Department of Nutrition, University of North Carolina at Chapel Hill, Chapel Hill,

North Carolina, USA

${ }^{24}$ Department of Nutritional Sciences \& Center for Childhood Obesity Research,

Pennsylvania State University, University Park, Pennsylvania, USA

${ }^{25}$ MRC Epidemiology Unit, University of Cambridge, Cambridge, UK

${ }^{26}$ Research Center for Health Equity, Cedars-Sinai Medical Center, West Hollywood,

California, USA

${ }^{27}$ Grossman School of Medicine, New York University, New York, New York, USA

${ }^{28}$ Department of Global Public Health, Karolinska Institute, Stockholm, Sweden

${ }^{29}$ College of Nursing, University of Kentucky, Lexington, Kentucky, USA

${ }^{30}$ Faculty of Health and Sport Sciences, Department of Nutrition and Public Health, University of Agder, Kristiansand, Vest-Agder, Norway

${ }^{31}$ Department of Dietetics and Nutrition, Robert Stempel College of Public Health \& Social Work, Florida International University, Miami, Florida, USA

${ }^{32}$ Department of Epidemiology, Harvard University T H Chan School of Public Health, Boston, Massachusetts, USA

${ }^{33}$ Center for Clinical Research and Health Promotion, University of Puerto Rico

Medical Sciences Campus, San Juan, Puerto Rico, USA

${ }^{34}$ Social Protection and Health Division, Inter-American Development Bank, Santo Domingo, Distrito Nacional, Dominican Republic

${ }^{35}$ Department of Anthropology, University of North Carolina at Chapel Hill, Chapel Hill, North Carolina, USA

${ }^{36}$ Pediatric Diabetes and Metabolic Disorders Unit, University of Verona, Verona, Italy
${ }^{37}$ Division of Chronic Disease Research Across the Lifecourse, Department of Population Medicine, Harvard Medical School and Harvard Pilgrim Health Care Institute, Boston, Massachusetts, USA

${ }^{38}$ Department of Clinical Neuroscience, Karolinska Institute, Stockholm, Sweden

${ }^{39}$ Medical Sciences Campus, University of Puerto Rico, San Juan, Puerto Rico, USA

${ }^{40}$ Social Protection and Health Division, Inter-American Development Bank,

Washington, District of Columbia, USA

${ }^{41}$ Department of Human Nutrition, Food and Animal Sciences, University of Hawaii,

Honolulu, Hawaii, USA

${ }^{42}$ Department of Preventive Medicine, University of Southern California, Los Angeles, California, USA

${ }^{43}$ Department of Pediatrics, Jacobs School of Medicine and Biomedical Sciences, University at Buffalo, Buffalo, New York, USA

${ }^{44}$ Better Start National Science Challenge, University of Otago, Dunedin, New Zealand

Twitter Kylie E Hunter @KylieEHunter, Brittany J Johnson @brittanyjayne8, Seema Mihrshahi @DrSeemaM, Kylie D Hesketh @KylieHesketh, Sharleen L O'Reilly @ oreillysharleen, Nina Cecilie Øverby @0verbyNina and Anna Lene Seidler @ LeneSeidler

Acknowledgements The authors thank Slavica Berber for guidance on the search strategy, and Jonathan Williams for his project management support. We would also like to acknowledge the NHMRC Centre of Research Excellence in Early Prevention of Obesity in Childhood (EPOCH CRE), who supported the pilot and foundational work for this project. Lastly, we thank Maria Luisa Garmendia and Camila Corvalan for their feedback on an earlier version of this protocol.

Contributors ALS together with KEH, BJJ, LA, RG conceived the idea for the study. $\mathrm{KEH}, \mathrm{BJJ}, \mathrm{ALS}, \mathrm{LA}, \mathrm{RG}$ developed the research question and protocol registration. KEH wrote the first draft of the manuscript. KEH, BJJ, ALS, RG, LA developed the eligibility criteria and search strategy. KEH, MA, AB, BJJ, SL, ALS performed the search and screening. AH, CR, CTW, DE, DAO'C, IM, KPR, LAB, LPS, LMW, MS-S, PC, RT, SM, ST, WS provided critical review and feedback at each stage of the process. All authors critically revised the manuscript for intellectual content, and agreed and approved the final manuscript. KEH is the guarantor of the review.

Funding This work was supported by the Australian National Health and Medical Research Council (NHMRC) Ideas Grant TOPCHILD (Transforming Obesity Prevention for CHILDren): Looking into the black box of interventions (GNT1186363). Funders had no role in developing this protocol. Individual authors declare the following funding: ALT reports funding from NIH R01HD073237; AML reports funding from NIH National Center for Advancing Translational Science through grant \# UL1TR000117 and UL1TR001998; BJT reports funding from Health Research Council of New Zealand; CGA reports funding from The PepsiCo Foundation; CP reports funding from National Institutes of Health, Robert Wood Johnson Foundation, World Health Organization, US Department of Agriculture; COS reports funding from University of Cincinnati University Research Council; DAOC is supported by an Australian National Health and Medical Research Council (NHMRC) Translating Research into Practice Fellowship (APP1168749); E0 reports the PROBIT study was supported by grant MOP-53155 from the Canadian Institutes of Health Research and grant R01 HD050758 from the US National Institutes of Health; IMP reports funding from grant R01DK088244 from the United States National Institute of Diabetes and Digestive and Kidney Diseases; JCB reports funding from US Department of Agriculture; JKL and LTK reports funding from Fonds NutsOhra awarded (100.939); JSS reports funding from NIH NIDDK, NIH NHLBI, PCORI; JLT is an employee of USDA ARS and the Agency did fund the Delta Healthy Sprouts Trial (Project 6401-5300-003-00D); KdIH reports funding from 1R01HD092483-01 (MPI: de la Haye, Salvy), NIH/NICHD; KDH is supported by an Australian Research Council Future Fellowship (FT130100637); LMW reports funding from NHMRC (\#393112; $\# 1003780$; \#1169823); LW is supported by a NHMRC Career Development and NHF Future Leader Fellowship; MB reports HAPPY was funded by a UK NIHR Programme Grant for Applied Research (project number RP-PG-0407-10044); MCR reports The Baby Act Trial was sponsored by the Center for Collaborative Research in Health Disparities under grant U54 MD007600 of the National Institute on Minority Health and Health Disparities from the National Institutes of Health; MJM reports funding from USDA AFRI 2011-68001-30207; NCØ reports their original study was partly funded by the Norwegian Women's Public Health Association, who had no influence on any part of the study design, implementation and evaluation; RKG is a Chief Investigator on the Early Prevention of Obesity in Childhood, NHMRC Centre for Research Excellence (1101675); RSG is supported by the National Institute of Food and Agriculture/US Department of Agriculture, award number 2011-6800130207 , and the National Institutes of Health/National Institute of Child Health and 
Human Development through a K23 Mentored Patient-Oriented Research Career Development Award (K23HD081077; principal investigator: Rachel S. Gross); RL reports funding from UK NPRI (National Prevention Research Initiative), MRC PHIND (Public Health Intervention Development programme); SLOR reports funding from European Unions Horizon 2020 Research and Innovation Programme (Grant Agreement no. 847984) and Australia National Health and Medical Research Council (NHMRC) (Grant application no. APP1194234); S-JS reports funding from NIMHD U54MD000502 (MPI: Salvy \& Dutton Project \#2), NICHD R01HD092483 (MPI: Salvy \& de la Haye); SA-F is a co-investigator on the current INSIGHT grant which follows participants to ages 6 and 9: NIH 2R01DK088244; ABP-E reports the SPOON program in Guatemala is funded by the Inter-American Development Bank with donations of The Government of Japan and The PepsiCo Foundation.

Competing interests $A B, A L S, B J J, K E H, M A, R K G$, SL and LPS reports grants from NHMRC Ideas Grant TOPCHILD (Transforming Obesity Prevention for CHILDren) (GNT1186363); APE and CGA reports grants administered by the Inter-American Development Bank from The Government of Japan and The PepsiCo Foundation; ALT reports grants from National Institute of Health; BJT reports grants from NZ Health Research Council; EO reports grants from the US National Institutes of Health, and the Canadian Institutes for Health Research; IMP reports grants from NIH/NIDDK; JSS reports grants from PCORI, NIH NIDDK and NHLBI, and personal fees from Danone Organic, American Academy of Pediatrics, and Lets Move Maine; LTK and JKL reports grants from Fonds NutsOhra; MCR reports grants from National Institute on Minority Health and Health Disparities-National Institutes of Health/ Center for Collaborative Research in Health Disparities, and personal fees from Rhythm Pharmaceuticals; RSG reports grants from US Department of Agriculture and $\mathrm{NIH} / \mathrm{NICHD}$.

Patient and public involvement statement The TOPCHILD Collaboration involves a broad range of stakeholders including health professionals, policy-makers and trialists. In addition, the Advisory Group includes a parent representative and intervention facilitator/nurse. They have given input into and feedback on this protocol and will be involved in discussion and interpretation of results.

\section{Patient consent for publication Not applicable.}

Provenance and peer review Not commissioned; externally peer reviewed.

Supplemental material This content has been supplied by the author(s). It has not been vetted by BMJ Publishing Group Limited (BMJ) and may not have been peer-reviewed. Any opinions or recommendations discussed are solely those of the author(s) and are not endorsed by BMJ. BMJ disclaims all liability and responsibility arising from any reliance placed on the content. Where the content includes any translated material, BMJ does not warrant the accuracy and reliability of the translations (including but not limited to local regulations, clinical guidelines, terminology, drug names and drug dosages), and is not responsible for any error and/or omissions arising from translation and adaptation or otherwise.

Open access This is an open access article distributed in accordance with the Creative Commons Attribution Non Commercial (CC BY-NC 4.0) license, which permits others to distribute, remix, adapt, build upon this work non-commercially, and license their derivative works on different terms, provided the original work is properly cited, appropriate credit is given, any changes made indicated, and the use is non-commercial. See: http://creativecommons.org/licenses/by-nc/4.0/.

\section{ORCID iDs}

Kylie E Hunter http://orcid.org/0000-0002-2796-9220

Brittany J Johnson http://orcid.org/0000-0001-5492-9219

Denise A 0'Connor http://orcid.org/0000-0002-6836-122X

Kylie D Hesketh http://orcid.org/0000-0002-2702-7110

Nina Cecilie Øverby http://orcid.org/0000-0002-1871-041X

Anna Lene Seidler http://orcid.org/0000-0002-0027-1623

\section{REFERENCES}

1 World Health Organization. Taking action on childhood obesity. Geneva, Switzerland: WHO, 2018.

2 World Health Organization. Report of the Comission on ending childhood obesity. Geneva, Switzerland: WHO, 2016.

3 United Nations Children's Fund (UNICEF), World Health Organization, International Bank for Reconstruction and Development/The World Bank. Levels and trends in child malnutrition: key findings of the 2020 edition of the joint child malnutrition estimates. Geneva: World Health Organization, 2020.

4 UNICEF. The State of the World's Children 2019. Children, Food and Nutrition: Growing well in a changing world. New York: UNICEF, 2019.
5 Di Cesare M, Sorić M, Bovet P, et al. The epidemiological burden of obesity in childhood: a worldwide epidemic requiring urgent action. BMC Med 2019;17:212.

6 Guerrero AD, Mao C, Fuller B, et al. Racial and ethnic disparities in early childhood obesity: growth trajectories in body mass index. $J$ Racial Ethn Health Disparities 2016;3:129-37.

7 Kumanyika SK. Unraveling common threads in obesity risk among racial/ethnic minority and migrant populations. Public Health 2019;172:125-34.

8 Simmonds M, Llewellyn A, Owen CG, et al. Predicting adult obesity from childhood obesity: a systematic review and meta-analysis. Obes Rev 2016;17:95-107.

9 Geserick M, Vogel M, Gausche R, et al. Acceleration of BMI in early childhood and risk of sustained obesity. N Engl J Med Overseas Ed 2018;379:1303-12.

10 Halfon N, Larson K, Slusser W. Associations between obesity and comorbid mental health, developmental, and physical health conditions in a nationally representative sample of US children aged 10 to 17. Acad Pediatr 2013;13:6-13.

11 Mihrshahi S, Gow ML, Baur LA. Contemporary approaches to the prevention and management of paediatric obesity: an Australian focus. Med J Aust 2018;209:267-74.

12 Wolfenden L, Ezzati M, Larijani B, et al. The challenge for global health systems in preventing and managing obesity. Obes Rev 2019;20:185-93.

13 Finkelstein EA, Graham WCK, Malhotra R. Lifetime direct medical costs of childhood obesity. Pediatrics 2014;133:854-62.

14 Redsell SA, Edmonds B, Swift JA, et al. Systematic review of randomised controlled trials of interventions that AIM to reduce the risk, either directly or indirectly, of overweight and obesity in infancy and early childhood. Matern Child Nutr 2016;12:24-38.

15 Hurley KM, Cross MB, Hughes SO. A systematic review of responsive feeding and child obesity in high-income countries. $J$ Nutr 2011:141:495-501.

16 Spill MK, Callahan EH, Shapiro MJ, et al. Caregiver feeding practices and child weight outcomes: a systematic review. Am J Clin Nutr 2019;109:990S-1002.

17 Porter RM, Tindall A, Gaffka BJ, et al. A review of modifiable risk factors for severe obesity in children ages 5 and under. Child Obes 2018;14:468-76.

18 Arenz S, Rückerl R, Koletzko B, et al. Breast-Feeding and childhood obesity-a systematic review. Int J Obes 2004;28:1247-56.

19 Lefebvre CM, John RM. The effect of breastfeeding on childhood overweight and obesity: a systematic review of the literature. J Am Assoc Nurse Pract 2014;26:386-401.

20 Qiao J, Dai L-J, Zhang Q, et al. A meta-analysis of the association between breastfeeding and early childhood obesity. J Pediatr Nurs 2020;53:57-66.

21 Weng SF, Redsell SA, Swift JA, et al. Systematic review and metaanalyses of risk factors for childhood overweight identifiable during infancy. Arch Dis Child 2012;97:1019-26.

22 Woo Baidal JA, Locks LM, Cheng ER, et al. Risk factors for childhood obesity in the first 1,000 days: a systematic review. Am J Prev Med 2016:50:761-79.

23 Yan J, Liu L, Zhu Y, et al. The association between breastfeeding and childhood obesity: a meta-analysis. BMC Public Health 2014;14:1267.

24 Vail B, Prentice P, Dunger DB, et al. Age at weaning and infant growth: primary analysis and systematic review. J Pediatr 2015; $167: 317-24$

25 Jiménez-Pavón D, Kelly J, Reilly JJ. Associations between objectively measured habitual physical activity and adiposity in children and adolescents: systematic review. Int $J$ Pediatr Obes 2010;5:3-18

26 Pate RR, Hillman CH, Janz KF, et al. Physical activity and health in children younger than 6 years: a systematic review. Med Sci Sports Exerc 2019;51:1282-91.

27 Timmons BW, Leblanc AG, Carson V, et al. Systematic review of physical activity and health in the early years (aged 0-4 years). Appl Physiol Nutr Metab 2012;37:773-92.

28 Wen LM, Baur LA, Rissel C, et al. Correlates of body mass index and overweight and obesity of children aged 2 years: findings from the healthy beginnings trial. Obesity 2014;22:1723-30.

29 Cox R, Skouteris $\mathrm{H}$, Rutherford $\mathrm{L}$, et al. Television viewing, television content, food intake, physical activity and body mass index: a crosssectional study of preschool children aged 2-6 years. Health Promot J Austr 2012;23:58-62.

30 Jochem C, Schmid D, Leitzmann MF. Sedentary Behaviour and Adiposity. In: Leitzmann MF, Jochem C, Schmid D, eds. Sedentary Behav Epidemiol, 2018: 155-78. 
31 Carter PJ, Taylor BJ, Williams SM, et al. Longitudinal analysis of sleep in relation to $\mathrm{BMI}$ and body fat in children: the flame study. BMJ 2011;342:d2712.

32 Felső R, Lohner S, Hollódy K, et al. Relationship between sleep duration and childhood obesity: systematic review including the potential underlying mechanisms. Nutr Metab Cardiovasc Dis 2017;27:751-61.

33 Miller MA, Kruisbrink M, Wallace J, et al. Sleep duration and incidence of obesity in infants, children, and adolescents: a systematic review and meta-analysis of prospective studies. Sleep 2018;41.

34 Morrissey B, Taveras E, Allender S, et al. Sleep and obesity among children: a systematic review of multiple sleep dimensions. Pediatr Obes 2020;15:e12619.

35 Sluggett L, Wagner SL, Harris RL. Sleep duration and obesity in children and adolescents. Can J Diabetes 2019;43:146-52.

36 Harskamp-van Ginkel MW, Chinapaw MJM, Harmsen IA, et al. Sleep during infancy and associations with childhood body composition: a systematic review and narrative synthesis. Child Obes 2020;16:94-116.

37 Ziauddeen N, Wilding S, Roderick PJ, et al. Predicting the risk of childhood overweight and obesity at 4-5years using population-level pregnancy and early-life healthcare data. BMC Med 2020;18:105.

38 Mukhopadhyay S, Bryan M, Dhudasia MB, et al. Intrapartum group B streptococcal prophylaxis and childhood weight gain. Arch Dis Child Fetal Neonatal Ed 2021;106:649-56.

39 Askie LM, Espinoza D, Martin A, et al. Interventions commenced by early infancy to prevent childhood obesity-The epoch collaboration: an individual participant data prospective meta-analysis of four randomized controlled trials. Pediatr Obes 2020;15:e12618.

40 Ash T, Agaronov A, Young Ta'Loria, et al. Family-Based childhood obesity prevention interventions: a systematic review and quantitative content analysis. Int J Behav Nutr Phys Act 2017;14:113.

41 Brown T, Moore TH, Hooper L, et al. Interventions for preventing obesity in children. Cochrane Database Syst Rev 2019;7:CD001871.

42 Narzisi K, Simons J. Interventions that prevent or reduce obesity in children from birth to five years of age: a systematic review. J Child Health Care 2021;25:320-34.

43 Blake-Lamb TL, Locks LM, Perkins ME, et al. Interventions for childhood obesity in the first 1,000 days a systematic review. Am J Prev Med 2016;50:780-9.

44 Bleich SN, Vercammen KA, Zatz LY, et al. Interventions to prevent global childhood overweight and obesity: a systematic review. Lancet Diabetes Endocrinol 2018;6:332-46.

45 Grobler L, Visser M, Siegfried N. Healthy life trajectories initiative: summary of the evidence base for pregnancy-related interventions to prevent overweight and obesity in children. Obes Rev 2019;20 Suppl 1:18-30.

46 Hennessy M, Heary C, Laws R, et al. The effectiveness of health professional-delivered interventions during the first 1000 days to prevent overweight/obesity in children: a systematic review. Obes Rev 2019;20:1691-707.

47 Haire-Joshu D, Tabak R. Preventing obesity across generations: evidence for early life intervention. Annu Rev Public Health 2016;37:253-71.

48 Lillycrop KA, Burdge GC. Epigenetic changes in early life and future risk of obesity. Int J Obes 2011;35:72-83.

49 Brookes ST, Whitely E, Egger M, et al. Subgroup analyses in randomized trials: risks of subgroup-specific analyses; power and sample size for the interaction test. J Clin Epidemiol 2004;57:229-36.

50 Egger M, Smith GD. Meta-Analysis. Potentials and promise. BMJ 1997;315:1371-4.

51 Seidler AL, Hunter KE, Espinoza D, et al. Quantifying the advantages of conducting a prospective meta-analysis (PMA): a case study of early childhood obesity prevention. Trials 2021;22:78.

52 Tierney J, Stewart L, Clarke M. Chapter 26: Individual participant data. In: Higgins J, Thomas J, Chandler J, eds. Cochrane Handbook for systematic reviews of interventions version 6.0. Cochrane, 2019.

53 Seidler AL, Hunter KE, Cheyne S, et al. A guide to prospective metaanalysis. BMJ 2019;9:15342.

54 Moher D, Shamseer L, Clarke M, et al. Preferred reporting items for systematic review and meta-analysis protocols (PRISMA-P) 2015 statement. Syst Rev 2015;4:1.
55 Dodd JM, Grivell RM, Louise J, et al. The effects of dietary and lifestyle interventions among pregnant women who are overweight or obese on longer-term maternal and early childhood outcomes: protocol for an individual participant data (IPD) meta-analysis. Syst Rev 2017;6:51.

56 McKenzie JE, Brennan SE, Ryan RE. Chapter 3: Defining the criteria for including studies and how they will be grouped for the synthesis. In: Higgins JPT, Thomas J, Chandler J, eds. Cochrane Handbook for systematic reviews of interventions version 6.1. Cochrane, 2021. www.training.cochrane.org/handbook2020

57 Sterne JAC, Savović J, Page MJ, et al. Rob 2: a revised tool for assessing risk of bias in randomised trials. BMJ 2019;366:14898.

58 Schünemann HJ, Higgins JPT, Vist GE. Chapter 14: Completing 'Summary of findings' tables and grading the certainty of the evidence. In: Higgins JPT, Thomas J, Chandler J, eds. Cochrane Handbook for systematic reviews of interventions version 6.1. Cochrane, 2020. www.training.cochrane.org/handbook2020

59 Guyatt G, Oxman AD, Akl EA, et al. Grade guidelines: 1. IntroductionGRADE evidence profiles and summary of findings tables. J Clin Epidemiol 2011;64:383-94.

60 World Health Organization. WHO child growth standards: growth velocity based on weight, length and head circumference: methods and development 2009 http://www.who.int/childgrowth/en/

61 Perng W, Ringham BM, Glueck DH, et al. An observational cohort study of weight- and length-derived anthropometric indicators with body composition at birth and 5 Mo: the healthy start study. Am J Clin Nutr 2017;106:559-67.

62 Roy SM, Fields DA, Mitchell JA, et al. Body mass index is a better indicator of body composition than Weight-for-Length at age 1 month. J Pediatr 2019;204:77-83.

63 Roy SM, Spivack JG, Faith MS, et al. Infant BMI or Weight-for-Length and obesity risk in early childhood. Pediatrics 2016;137:e20153492.

64 Woo JG, Daniels SR. Assessment of body mass index in infancy: it is time to revise our guidelines. J Pediatr 2019;204:10-11.

65 Smego A, Woo JG, Klein J, et al. High body mass index in infancy may predict severe obesity in early childhood. J Pediatr 2017;183:87-93.

66 WHO Multicentre Growth Reference Study Group. Who child growth standards based on length/height, weight and age. Acta Paediatr Supp/ 2006;450:76-85.

67 Riley RD, Debray TPA, Fisher D, et al. Individual participant data meta-analysis to examine interactions between treatment effect and participant-level covariates: statistical recommendations for conduct and planning. Stat Med 2020;39:2115-37.

68 Burke DL, Ensor J, Riley RD. Meta-Analysis using individual participant data: one-stage and two-stage approaches, and why they may differ. Stat Med 2017;36:855-75.

69 Riley RD, Steyerberg EW. Meta-Analysis of a binary outcome using individual participant data and aggregate data. Res. Synth. Method 2010;1:2-19.

70 Deeks JJ, Higgins JPT, Altman DG. Chapter 10: Analysing data and undertaking meta-analyses. In: Higgins JPT, Thomas J, Chandler $\mathrm{J}$, eds. Cochrane Handbook for systematic reviews of interventions version $6.1,2020$. www.training.cochrane.org/handbook

71 R Core Team. R: a language and environment for statistical computing. $R$ foundation for statistical computing. Vienna, Austria, 2020. https://www.R-project.org/

72 Schulz KF, Grimes DA. Multiplicity in randomised trials II: subgroup and interim analyses. Lancet 2005;365:1657-61.

73 Stewart LA, Parmar MK. Meta-Analysis of the literature or of individual patient data: is there a difference? Lancet 1993;341:418-22.

74 Tierney JF, Fisher DJ, Burdett S, et al. Comparison of aggregate and individual participant data approaches to meta-analysis of randomised trials: an observational study. PLoS Med 2020;17:e1003019.

75 Johnson BJ, Hunter KE, Golley R, et al. Unpacking the behavioural components and delivery features of early childhood obesity prevention interventions in the TOPCHILD collaboration: a systematic review and intervention coding protocol. BMJ Open 2021. 
Supplementary file 1: PRISMA-P checklist

\section{PRISMA-P (Preferred Reporting Items for Systematic review and Meta-Analysis Protocols) 2015} checklist: recommended items to address in a systematic review protocol*

\begin{tabular}{lccc}
\hline $\begin{array}{l}\text { Section and } \\
\text { topic }\end{array}$ & $\begin{array}{c}\text { Item } \\
\text { No }\end{array}$ & Checklist item & Page No \\
\hline
\end{tabular}

\section{ADMINISTRATIVE INFORMATION}

Title:

1a Identify the report as a protocol of a systematic review $\quad 1,3$

Update $\quad 1 b$ If the protocol is for an update of a previous systematic review, identify as such

$\mathrm{n} / \mathrm{a}$

$\begin{array}{llll}\text { Registration } 2 \text { If registered, provide the name of the registry (such as PROSPERO) and registration } & 4\end{array}$ number

Authors:

Contact 3a Provide name, institutional affiliation, e-mail address of all protocol authors; provide physical mailing address of corresponding author

3b Describe contributions of protocol authors and identify the guarantor of the review 19

Contributions

\begin{tabular}{llll}
\hline Amendments $\quad 4$ & $\begin{array}{l}\text { If the protocol represents an amendment of a previously completed or published } \\
\text { protocol, identify as such and list changes; otherwise, state plan for documenting } \\
\text { important protocol amendments }\end{array}$ & $\mathrm{n} / \mathrm{a}$ \\
&
\end{tabular}

Support:

$\begin{array}{lll}\text { Sources } & 5 \mathrm{a} \text { Indicate sources of financial or other support for the review } & 20\end{array}$

Sponsor $5 b$ Provide name for the review funder and/or sponsor 20

Role of 5c Describe roles of funder(s), sponsor(s), and/or institution(s), if any, in developing the 20 sponsor or protocol

funder

\section{INTRODUCTION}

\begin{tabular}{llll}
\hline Rationale & 6 & Describe the rationale for the review in the context of what is already known & $5-8$ \\
\hline Objectives & 7 & $\begin{array}{l}\text { Provide an explicit statement of the question(s) the review will address with reference to } 8 \\
\text { participants, interventions, comparators, and outcomes (PICO) }\end{array}$ \\
\hline
\end{tabular}

\section{METHODS}

\begin{tabular}{|c|c|c|c|}
\hline Eligibility criteria & 8 & $\begin{array}{l}\text { Specify the study characteristics (such as PICO, study design, setting, time frame) and } \\
\text { report characteristics (such as years considered, language, publication status) to be used } \\
\text { as criteria for eligibility for the review }\end{array}$ & $8-10$ \\
\hline $\begin{array}{l}\text { Information } \\
\text { sources }\end{array}$ & 9 & $\begin{array}{l}\text { Describe all intended information sources (such as electronic databases, contact with } \\
\text { study authors, trial registers or other grey literature sources) with planned dates of } \\
\text { coverage }\end{array}$ & 10 \\
\hline Search strategy & 10 & $\begin{array}{l}\text { Present draft of search strategy to be used for at least one electronic database, including } \\
\text { planned limits, such that it could be repeated }\end{array}$ & $\begin{array}{l}\text { Supplementary } \\
\text { file } 2\end{array}$ \\
\hline \multicolumn{4}{|l|}{ Study records: } \\
\hline $\begin{array}{l}\text { Data } \\
\text { management }\end{array}$ & $11 \mathrm{a}$ & $\begin{array}{l}\text { Describe the mechanism(s) that will be used to manage records and data throughout the } \\
\text { review }\end{array}$ & 11 \\
\hline $\begin{array}{l}\text { Selection } \\
\text { process }\end{array}$ & $11 b$ & $\begin{array}{l}\text { State the process that will be used for selecting studies (such as two independent } \\
\text { reviewers) through each phase of the review (that is, screening, eligibility and inclusion in } \\
\text { meta-analysis) }\end{array}$ & 10 \\
\hline $\begin{array}{l}\text { Data } \\
\text { collection } \\
\text { process }\end{array}$ & $11 \mathrm{c}$ & $\begin{array}{l}\text { Describe planned method of extracting data from reports (such as piloting forms, done } \\
\text { independently, in duplicate), any processes for obtaining and confirming data from } \\
\text { investigators }\end{array}$ & 11 \\
\hline Data items & 12 & $\begin{array}{l}\text { List and define all variables for which data will be sought (such as PICO items, funding } \\
\text { sources), any pre-planned data assumptions and simplifications }\end{array}$ & $12-14$ \\
\hline $\begin{array}{l}\text { Outcomes and } \\
\text { prioritization }\end{array}$ & 13 & $\begin{array}{l}\text { List and define all outcomes for which data will be sought, including prioritization of main } \\
\text { and additional outcomes, with rationale }\end{array}$ & $12-14$ \\
\hline
\end{tabular}




\begin{tabular}{|c|c|c|c|}
\hline $\begin{array}{l}\text { Risk of bias in } \\
\text { individual } \\
\text { studies }\end{array}$ & 14 & $\begin{array}{l}\text { Describe anticipated methods for assessing risk of bias of individual studies, including } \\
\text { whether this will be done at the outcome or study level, or both; state how this } \\
\text { information will be used in data synthesis }\end{array}$ & 11 \\
\hline \multirow[t]{4}{*}{ Data synthesis } & $15 a$ & Describe criteria under which study data will be quantitatively synthesised & 14 \\
\hline & $15 b$ & $\begin{array}{l}\text { If data are appropriate for quantitative synthesis, describe planned summary measures, } \\
\text { methods of handling data and methods of combining data from studies, including any } \\
\text { planned exploration of consistency (such as } 1^{2} \text {, Kendall's } \tau \text { ) }\end{array}$ & $14-15$ \\
\hline & $15 \mathrm{c}$ & $\begin{array}{l}\text { Describe any proposed additional analyses (such as sensitivity or subgroup analyses, } \\
\text { meta-regression) }\end{array}$ & 12,16 \\
\hline & $15 d$ & If quantitative synthesis is not appropriate, describe the type of summary planned & $\mathrm{n} / \mathrm{a}$ \\
\hline Meta-bias(es) & 16 & $\begin{array}{l}\text { Specify any planned assessment of meta-bias(es) (such as publication bias across studies, } \\
\text { selective reporting within studies) }\end{array}$ & 15 \\
\hline $\begin{array}{l}\text { Confidence in } \\
\text { cumulative } \\
\text { evidence }\end{array}$ & 17 & Describe how the strength of the body of evidence will be assessed (such as GRADE) & $11-12$ \\
\hline
\end{tabular}

* It is strongly recommended that this checklist be read in conjunction with the PRISMA-P Explanation and Elaboration (cite when available) for important clarification on the items. Amendments to a review protocol should be tracked and dated. The copyright for PRISMA-P (including checklist) is held by the PRISMA-P Group and is distributed under a Creative Commons Attribution Licence 4.0.

From: Shamseer L, Moher D, Clarke M, Ghersi D, Liberati A, Petticrew M, Shekelle P, Stewart L, PRISMA-P Group. Preferred reporting items for systematic review and meta-analysis protocols (PRISMA-P) 2015: elaboration and explanation. BMJ. 2015 Jan 2;349(jan02 1):g764 
Supplementary file 2: TOPCHILD search strategy

\section{Ovid MEDLINE}

1. obesity/

2. pediatric obesity/

3. overweight/

4. Weight Gain/

5. body-weight trajectory/

6. Body mass index/

7. Adiposity/

8. Body weight/

9. Body Weight Changes/

10. Skinfold thickness/

11. Waist-hip-ratio/

12. Waist circumference/

13. obes*.tw

14. (overweight or over weight or over-weight).tw

15. (weight gain).tw

16. (BMI or body mass index).tw

17. adiposity.tw

18. (body weight).tw

19. (weight change\$).tw

20. (skin fold thickness).tw

21. (waist-hip ratio).tw

22. (waist circumference).tw

23. 1 or 2 or 3 or 4 or 5 or 6 or 7 or 8 or 9 or 10 or 11 or 12 or 13 or 14 or 15 or 16 or 17 or 18 or 19 or 20 or 21 or 22

24. child health services/

25. early intervention, educational/

26. maternal-child health services/

27. Maternal-Child Health Centers/

28. maternal health services/

29. Mother-Child Relations/

30. preventive health services/

31 . health education/

32. health promotion/

33. ((behaviour or behavior) and change).ti,ab

34. ((behavio?r*) adj (therapy or modif* or strateg* or intervention* or advice or program* or class* or counsel* or educat* or instruct* or teach* or train* or guidance or lesson* or workshop* or module* or consultation* or session*)).ti,ab

35. ((lifestyle or life style) adj (chang* or modif* or strateg* or intervention* or advice or program* or class* or counsel* or educat* or instruct* or teach* or train* or guidance or lesson* or workshop* or module* or consultation* or session*)).ti,ab

36. (peer adj2 support).ti,ab

37. education* adj1 (intervention* or program* or class* or counsel* or teach* or workshop* or module* or consultation* or session*).ti,ab

38. 24 OR 25 OR 26 OR 27 OR 28 OR 29 OR 30 OR 31 OR 32 OR 33 OR 34 OR 35 OR 36 OR 37

39. Breastfeeding/

40. Infant Nutritional Physiological Phenomena/

41. Infant Food/

42. Diet, Healthy/ 
43. ((diet* or nutrition or feeding) adj (modif* or strateg* or intervention* or advice or program* or class* or counsel* or educat* or instruct* or teach* or train* or guidance or lesson* or workshop* or module* or consultation* or session*)).ti,ab

44. ((child or toddler or infant\$) adj1 (food or feeding or nutrition\$)).ti,ab

45. ((responsive or complementary) adj1 feeding).ti,ab

46. (healthy eating).ti,ab

47. Feeding behavior/

48. 39 OR 40 OR 41 OR 42 OR 43 OR 44 OR 45 OR 46 OR 47

49. Motor activity/

50. Exercise/

51. Sedentary Behavior/

52. (physical activity or physical inactivity).ti,ab

53. sedentary behavio?r.ti,ab

54. (screen time).ti,ab

55. play.ab,ti

56. "tummy time".ab,ti

57. 49 OR 50 OR 51 OR 52 OR 53 OR 54 OR 55 OR 56

58. Sleep/

59. Sleep.ti,ab

60. 58 OR 59

61. 38 OR 48 OR 57 OR 60

62. 23 AND 56

63. exp child/

64. exp infant/

65. (babies or baby or boy? or child* or girl? or infan* or kid? or neonat* or neo-nat* or newborn* or new-born* or paediatric* or peadiatric* or pediatric* or perinat* or toddler?).ti,ab,kf.

66. (pregnan* or perinatal* OR prenatal* OR antenatal OR postnatal*).ti,ab,kf

67. Parents/

68. (parent\$ or care giver or caregiver or guardian or family or families or mother\$ or father\$ OR maternal OR paternal).tw

69. 63 or 64 or 65 or 66 or 67 or 68

70. 62 AND 69

71. (exp animals/ not humans.sh.) or (rat or rats or mouse or mice or rodent*).ti.

72. 70 not 71

73. randomized controlled trial.pt.

74. controlled clinical trial.pt.

75. randomi\#ed.ab.

76. clinical trials as topic.sh.

77. randomly.ab.

78. trial.ti.

79. 73 or 74 or 75 or 76 or 77 or 78

80. 72 AND 79

\section{Embase Classic+Embase}

1. obesity/

2. pediatric obesity/

3. overweight/

4. Weight Gain/

5. body-weight trajectory/

6. Body mass index/ 
7. Adiposity/

8. Body weight/

9. Body Weight Changes/

10. Skinfold thickness/

11. Waist-hip-ratio/

12. Waist circumference/

13. obes*.tw.

14. (overweight or over weight or over-weight).tw.

15. weight gain.tw.

16. (BMI or body mass index).tw.

17. adiposity.tw.

18. body weight.tw.

19. weight change\$.tw.

20. skin fold thickness.tw.

21. waist-hip ratio.tw.

22. waist circumference.tw.

23. 1 or 2 or 3 or 4 or 5 or 6 or 7 or 8 or 9 or 10 or 11 or 12 or 13 or 14 or 15 or 16 or 17 or 18 or 19 or 20 or 21 or 22

24. child health services/

25. early intervention, educational/

26. maternal-child health services/

27. Maternal-Child Health Centers/

28. maternal health services/

29. Mother-Child Relations/

30. preventive health services/

31. health education/

32. health promotion/

33. ((behaviour or behavior) and change).ti,ab.

34. (behavio?r* adj (therapy or modif* or strateg* or intervention* or advice or program* or class* or counsel* or educat* or instruct* or teach* or train* or guidance or lesson* or workshop* or module* or consultation* or session*)).ti,ab.

35. ((lifestyle or life style) adj (chang* or modif* or strateg* or intervention* or advice or program* or class* or counsel* or educat* or instruct* or teach* or train* or guidance or lesson* or workshop* or module* or consultation* or session*)).ti,ab.

36. (peer adj2 support).ti,ab.

37. (education* adj1 (intervention* or program* or class* or counsel* or teach* or workshop* or module* or consultation* or session*)).ti,ab. (high fat* or low fat* or fatty food*).ti,ab

38. 24 or 25 or 26 or 27 or 28 or 29 or 30 or 31 or 32 or 33 or 34 or 35 or 36 or 37

39. Breastfeeding/

40. Infant Nutritional Physiological Phenomena/

41. Infant Food/

42. Diet, Healthy/

43. ((diet* or nutrition or feeding) adj (modif* or strateg* or intervention* or advice or program* or class* or counsel* or educat* or instruct* or teach* or train* or guidance or lesson* or workshop* or module* or consultation* or session*)).ti,ab.

44. ((child or toddler or infant\$) adj1 (food or feeding or nutrition\$)).ti,ab.

45. ((responsive or complementary) adj1 feeding).ti,ab.

46. healthy eating.ti,ab.

47. Feeding behavior/

48. 39 or 40 or 41 or 42 or 43 or 44 or 45 or 46 or 47

49. Motor activity/ 
50. Exercise/

51. Sedentary Behavior/

52. (physical activity or physical inactivity).ti,ab.

53. sedentary behavio?r.ti,ab.

54. screen time.ti,ab.

55. play.ab,ti.

56. "tummy time".ab,ti.

57. 49 or 50 or 51 or 52 or 53 or 54 or 55 or 56

58. Sleep/

59. Sleep.ti,ab.

60. 58 or 59

61. 38 or 48 or 57 or 60

62. 23 and 61

63. exp child/

64. exp infant/

65. (babies or baby or boy? or child* or girl? or infan* or kid? or neonat* or neo-nat* or newborn* or new-born* or paediatric* or peadiatric* or pediatric* or perinat* or toddler?).ti,ab

66. (pregnan* or perinatal* or prenatal* or antenatal or postnatal*).ti,ab

67. Parents/

68. (parent\$ or care giver or caregiver or guardian or family or families or mother\$ or father\$ or maternal or paternal).tw.

69. 63 or 64 or 65 or 66 or 67 or 68

70. 62 and 69

71. (exp animals/ not humans.sh.) or (rat or rats or mouse or mice or rodent*).ti.

72. 70 not 71

73. exp clinical trial/

74. exp Randomized Controlled Trial/

75. randomization/

76. clinical trial.tw.

77. random\$.tw.

78. Comparative Study/

79. (comparison group\$ or control group\$).tw.

80.73 or 74 or 75 or 76 or 77 or 78 OR 79

81. 72 and 80

\section{EBM Reviews - Cochrane Central Register of Controlled Trials}

1. obesity/

2. pediatric obesity/

3. overweight/

4. Weight Gain/

5. body-weight trajectory/

6. Body mass index/

7. Adiposity/

8. Body weight/

9. Body Weight Changes/

10. Skinfold thickness/

11. Waist-hip-ratio/

12. Waist circumference/

13. obes*.tw.

14. (overweight or over weight or over-weight).tw.

15. weight gain.tw. 
16. (BMI or body mass index).tw.

17. adiposity.tw.

18. body weight.tw.

19. weight change\$.tw.

20. skin fold thickness.tw.

21. waist-hip ratio.tw.

22. waist circumference.tw.

23. 1 or 2 or 3 or 4 or 5 or 6 or 7 or 8 or 9 or 10 or 11 or 12 or 13 or 14 or 15 or 16 or 17 or 18 or 19 or 20 or 21 or 22

24. child health services/

25. early intervention, educational/

26. maternal-child health services/

27. Maternal-Child Health Centers/

28. maternal health services/

29. Mother-Child Relations/

30. preventive health services/

31. health education/

32. health promotion/

33. ((behaviour or behavior) and change).ti,ab.

34. (behavio?r* adj (therapy or modif* or strateg* or intervention* or advice or program* or class* or counsel* or educat* or instruct* or teach* or train* or guidance or lesson* or workshop* or module* or consultation* or session*)).ti,ab.

35. ((lifestyle or life style) adj (chang* or modif* or strateg* or intervention* or advice or program* or class* or counsel* or educat* or instruct* or teach* or train* or guidance or lesson* or workshop* or module* or consultation* or session*)).ti,ab.

36. (peer adj2 support).ti,ab.

37. (education* adj1 (intervention* or program* or class* or counsel* or teach* or workshop* or module* or consultation* or session*)).ti,ab.

38. 24 or 25 or 26 or 27 or 28 or 29 or 30 or 31 or 32 or 33 or 34 or 35 or 36 or 37

39. Breastfeeding/

40. Infant Nutritional Physiological Phenomena/

41. Infant Food/

42. Diet, Healthy/

43. ((diet* or nutrition or feeding) adj (modif* or strateg* or intervention* or advice or program* or class* or counsel* or educat* or instruct* or teach* or train* or guidance or lesson* or workshop* or module* or consultation* or session*)).ti,ab.

44. ((child or toddler or infant\$) adj1 (food or feeding or nutrition\$)).ti,ab.

45. ((responsive or complementary) adj1 feeding).ti,ab.

46. healthy eating.ti,ab.

47. Feeding behavior/

48. 39 or 40 or 41 or 42 or 43 or 44 or 45 or 46 or 47

49. Motor activity/

50. Exercise/

51. Sedentary Behavior/

52. (physical activity or physical inactivity).ti,ab.

53. sedentary behavio?r.ti,ab.

54. screen time.ti,ab.

55. play.ab,ti.

56. "tummy time".ab,ti.

57.49 or 50 or 51 or 52 or 53 or 54 or 55 or 56

58. Sleep/ 
59. Sleep.ti,ab.

60. 58 or 59

61. 38 or 48 or 57 or 60

62. 23 and 61

63. exp child/

64. exp infant/

65. (babies or baby or boy? or child* or girl? or infan* or kid? or neonat* or neo-nat* or newborn* or new-born* or paediatric* or peadiatric* or pediatric* or perinat* or toddler?).ti,ab.

66. (pregnan* or perinatal* or prenatal* or antenatal or postnatal*).ti,ab.

67. Parents/

68. (parent\$ or care giver or caregiver or guardian or family or families or mother\$ or father\$ or maternal or paternal).tw.

69. 63 or 64 or 65 or 66 or 67 or 68

70. 62 and 69

CINAHL Complete (EBSCO Host)

\begin{tabular}{|c|c|}
\hline S77 & S67 AND S75 \\
\hline S76 & S67 AND S75 \\
\hline S75 & S68 OR S69 OR S70 OR S71 OR S72 OR S73 OR S74 \\
\hline S74 & TX comparison group* \\
\hline S73 & TX random* \\
\hline S72 & (PT "CLINICAL TRIAL") \\
\hline S71 & (MH "Clinical Trials") \\
\hline S70 & (MH "Random Sample+") \\
\hline S69 & (MH "Random Assignment") \\
\hline S68 & (MH "Comparative Studies") \\
\hline S67 & S65 NOT S66 \\
\hline S66 & (MH "Animals+") \\
\hline S65 & S56 AND S64 \\
\hline S64 & S57 OR S58 OR S59 OR S60 OR S61 OR S62 OR S63 \\
\hline S63 & $\begin{array}{l}\text { (TI parent\$ or care giver or caregiver or guardian or family or families or mother\$ or } \\
\text { father\$ OR maternal OR paternal) OR (AB (parent\$ or care giver or caregiver or guardian or } \\
\text { family or families or mother\$ or father\$ OR maternal OR paternal) }\end{array}$ \\
\hline S62 & (MH "Parents") \\
\hline S61 & $\begin{array}{l}\text { (TI pregnan* or perinatal* or prenatal* or antenatal* or postnatal*) OR (AB pregnan* or } \\
\text { perinatal* or prenatal* or antenatal* or postnatal*) }\end{array}$ \\
\hline S60 & $\begin{array}{l}\text { (AB babies or baby or boy? or girl? or child* or infan* or kid? or neonat* or neo-nat* or } \\
\text { newborn* or new-born* or paediatric* or peadiatric* or pediatric* or perinat* or toddler?) }\end{array}$ \\
\hline S59 & $\begin{array}{l}\text { (TI babies or baby or boy? or girl? or child* or infan* or kid? or neonat* or neo-nat* or } \\
\text { newborn* or new-born* or paediatric* or peadiatric* or pediatric* or perinat* or toddler?) }\end{array}$ \\
\hline S58 & (MH "Infant+") \\
\hline S57 & (MH "Child+") \\
\hline S56 & S17 AND S55 \\
\hline S55 & S31 OR S44 OR S51 OR S54 \\
\hline S54 & S52 OR S53 \\
\hline S53 & (TI sleep) OR (AB sleep) \\
\hline S52 & (MH "Sleep") \\
\hline S51 & S45 OR S46 OR S47 OR S48 OR S49 OR S50 \\
\hline S50 & (TI "tummy time") OR (AB "tummy time") \\
\hline
\end{tabular}




\begin{tabular}{|c|c|}
\hline S49 & (TI play) OR (AB play) \\
\hline S48 & (TI screen time) OR (AB screen time) \\
\hline S47 & (TI sedentary behavio?r) or (AB sedentary behavio?r) \\
\hline S46 & (TI physical activity or physical inactivity) OR (AB physical activity or physical inactivity) \\
\hline S45 & (MH "Exercise") \\
\hline S44 & S32 OR S33 OR S34 OR S35 OR S36 OR S37 OR S38 OR S39 OR S40 OR S41 OR S42 OR S43 \\
\hline S43 & (MH "Eating Behavior") \\
\hline S42 & (TI healthy eating) OR (AB healthy eating) \\
\hline S41 & (TI "responsive feed*") OR (AB "responsive feed*") \\
\hline S40 & (TI "complementary feeding") OR (AB "complementary feeding") \\
\hline S39 & $\begin{array}{l}\text { (AB nutrition N2 modif*) or ( } A B \text { nutrition N2 strateg*) or ( } A B \text { nutrition N2 intervention*) or } \\
\text { (AB nutrition N2 advice) or ( } A B \text { nutrition N2 program*) or ( } A B \text { nutrition N2 class*) or ( } A B \\
\text { nutrition N2 counsel*) or ( } A B \text { nutrition N2 educat*) or ( } A B \text { nutrition N2 instruct*) or ( } A B \\
\text { nutrition N2 teach*) or ( } A B \text { nutrition N2 train*) or ( } A B \text { nutrition N2 guidance) or ( } A B \\
\text { nutrition N2 lesson*) or ( } A B \text { nutrition N2 workshop*) or ( } A B \text { nutrition N2 module*) or (AB } \\
\text { nutrition N2 consultation*) or (AB nutrition N2 sess ... }\end{array}$ \\
\hline S38 & $\begin{array}{l}\text { (AB diet* N2 modif*) or (AB diet* N2 strateg*) or (AB diet* N2 intervention*) or (AB diet* } \\
\text { N2 advice) or (AB diet* N2 program*) or (AB diet* N2 class*) or (AB diet* N2 counsel*) or } \\
\text { (AB diet* N2 educat*) or (AB diet* N2 instruct*) or (AB diet* N2 teach*) or (AB diet* N2 } \\
\text { train*) or (AB diet* N2 guidance) or (AB diet* N2 lesson*) or (AB diet* N2 workshop*) or (AB } \\
\text { diet* N2 module*) or (AB diet* N2 consultation*) or (AB diet* N2 session*) }\end{array}$ \\
\hline S37 & $\begin{array}{l}\text { (TI nutrition N2 modif*) or (TI nutrition N2 strateg*) or (TI nutrition N2 intervention*) or (TI } \\
\text { nutrition N2 advice) or (TI nutrition N2 program*) or (TI nutrition N2 class*) or (TI nutrition } \\
\text { N2 counsel*) or (TI nutrition N2 educat*) or (TI nutrition N2 instruct*) or (TI nutrition N2 } \\
\text { teach*) or (TI nutrition N2 train*) or (TI nutrition N2 guidance) or (TI nutrition N2 lesson*) or } \\
\text { (TI nutrition N2 workshop*) or (TI nutrition N2 module*) or (TI nutrition N2 consultation*) or } \\
\text { (TI nutrition N2 sess ... }\end{array}$ \\
\hline S36 & $\begin{array}{l}\text { (TI diet* N2 modif*) or (TI diet* N2 strateg*) or (TI diet* N2 intervention*) or (TI diet* N2 } \\
\text { advice) or (TI diet* N2 program*) or (TI diet* N2 class*) or (TI diet* N2 counsel*) or (TI diet* } \\
\text { N2 educat*) or (TI diet* N2 instruct*) or (TI diet* N2 teach*) or (TI diet* N2 train*) or (TI } \\
\text { diet* N2 guidance) or (TI diet* N2 lesson*) or (TI diet* N2 workshop*) or (TI diet* N2 } \\
\text { module*) or (TI diet* N2 consultation*) or (TI diet* N2 session*) }\end{array}$ \\
\hline S35 & (MH "Infant Feeding") \\
\hline S34 & (MH "Infant Food") \\
\hline S33 & (MH "Infant Nutritional Physiology") \\
\hline S32 & (MH "Breast Feeding") \\
\hline S31 & $\begin{array}{l}\text { S18 OR S19 OR S20 OR S21 OR S22 OR S23 OR S24 OR S25 OR S26 OR S27 OR S28 OR S29 OR } \\
\text { S30 }\end{array}$ \\
\hline S30 & (TI counselling or counseling) OR (AB counselling or counseling) \\
\hline S29 & (TI peer N2 support) OR (AB peer N2 support) \\
\hline S28 & (TI home visit) OR (AB home visit) \\
\hline S27 & $\begin{array}{l}\text { (TI education N2 intervention*) OR (TI education N2 program*) OR (TI education N2 class*) } \\
\text { OR (TI education N2 counsel*) OR (TI education N2 teach*) OR (TI education N2 workshop) } \\
\text { OR (TI education N2 module*) OR (TI education N2 consultation*) OR (TI education N2 } \\
\text { session*) (AB education N2 intervention*) OR (AB education N2 program*) OR (AB } \\
\text { education N2 class*) OR (AB education N2 counsel*) OR (AB education N2 teach*) OR (AB } \\
\text { education N2 workshop) OR (AB education N2 module*) OR (AB education N2 c... }\end{array}$ \\
\hline S26 & (MM "Behavior Modification") \\
\hline S25 & (MM "Behavioral Changes") \\
\hline
\end{tabular}




\begin{tabular}{|l|l|}
\hline S24 & $\begin{array}{l}\text { (TI behaviour change) OR (AB behaviour change) OR (TI behavior change) OR (AB behavior } \\
\text { change) }\end{array}$ \\
\hline S23 & (MH "Health Promotion") \\
\hline S22 & (MH "Health Education") \\
\hline S21 & (MH "Mother-Child Relations") OR (MH "Mother-Infant Relations") \\
\hline S20 & (MH "Maternal Health Services") OR (MH "Maternal-Child Health") \\
\hline S19 & (MH "Early Childhood Intervention") \\
\hline S18 & (MH "Child Health Services") \\
\hline S17 & $\begin{array}{l}\text { S1 OR S2 OR S3 OR S4 OR S5 OR S6 OR S7 OR S8 OR S9 OR S10 OR S11 OR S12 OR S13 OR S14 } \\
\text { OR S15 OR S16 }\end{array}$ \\
\hline S16 & (TI waist-hip ratio or waist circumference) OR (AB waist-hip ratio or waist circumference) \\
\hline S15 & (TI skin fold thickness) OR (AB skin fold thickness) \\
\hline S14 & (TI weight change*) OR (AB weight change*) \\
\hline S13 & (TI body weight) OR (AB body weight) \\
\hline S12 & (TI adiposity) OR (AB adiposity) \\
\hline S11 & (TI BMI or body mass index) OR (AB BMI or body mass index) \\
\hline S10 & (TI weight gain) OR (AB weight gain) \\
\hline S9 & (TI overweight or over weight) OR (AB overweight or over weight) \\
\hline S8 & (TI obese or obesity) OR (AB obese or obesity) \\
\hline S7 & (MH "Waist Circumference") \\
\hline S6 & (MH "Waist-Hip Ratio") \\
\hline S5 & (MH "Skinfold Thickness") \\
\hline S4 & (MH "Body Weight") \\
\hline S3 & (MH "Body Mass Index") \\
\hline S2 & (MH "Weight Gain") OR (MH "Body Weight Changes") \\
\hline S1 & (MH "Obesity") OR (MH "Pediatric Obesity") \\
\hline
\end{tabular}

\section{APA Psyclnfo}

\begin{tabular}{|l|l|}
\hline 1 & obesity/ \\
\hline 2 & overweight/ \\
\hline 3 & Weight Gain/ \\
\hline 4 & Body mass index/ \\
\hline 5 & Body weight/ \\
\hline 6 & obes*.tw. \\
\hline 7 & (overweight or over weight or over-weight).tw. \\
\hline 8 & weight gain.tw. \\
\hline 9 & (BMI or body mass index).tw. \\
\hline 10 & adiposity.tw. \\
\hline 11 & body weight.tw. \\
\hline 12 & weight change\$.tw. \\
\hline 13 & skin fold thickness.tw. \\
\hline 14 & waist-hip ratio.tw. \\
\hline 15 & waist circumference.tw. \\
\hline 16 & 1 or 2 or 3 or 4 or 5 or 6 or 7 or 8 or 9 or 10 or 11 or 12 or 13 or 14 or 15 \\
\hline 17 & Mother-Child Relations/ \\
\hline 18 & preventive health services/ \\
\hline 19 & health education/ \\
\hline 20 & health promotion/ \\
\hline
\end{tabular}


21 ((behaviour or behavior) and change).ti,ab.

22 (behavio?r* adj (therapy or modif* or strateg* or intervention* or advice or program* or class* or counsel* or educat* or instruct* or teach* or train* or guidance or lesson* or workshop* or module* or consultation* or session*)).ti,ab.

23 ((lifestyle or life style) adj (chang* or modif* or strateg* or intervention* or advice or program* or class* or counsel* or educat* or instruct* or teach* or train* or guidance or lesson* or workshop* or module* or consultation* or session*)).ti,ab.

24 (peer adj2 support).ti,ab.

25 (education* adj1 (intervention* or program* or class* or counsel* or teach* or workshop* or module* or consultation* or session*)).ti,ab.

2617 or 18 or 19 or 20 or 21 or 22 or 23 or 24 or 25

27 Breast Feeding/

28 ((diet* or nutrition or feeding) adj (modif* or strateg* or intervention* or advice or program* or class* or counsel* or educat* or instruct* or teach* or train* or guidance or lesson* or workshop* or module* or consultation* or session*)).ti,ab.

29 ((child or toddler or infant\$) adj1 (food or feeding or nutrition\$)).ti,ab.

30 ((responsive or complementary) adj1 feeding).ti,ab.

31 healthy eating.ti,ab.

32 Feeding behavior/

3327 or 28 or 29 or 30 or 31 or 32

34 Exercise/

35 Sedentary Behavior/

36 (physical activity or physical inactivity).ti,ab.

37 sedentary behavio?r.ti,ab.

38 screen time.ti,ab.

39 play.ab,ti.

40 "tummy time".ab,ti.

4134 or 35 or 36 or 37 or 38 or 39 or 40

42 Sleep/

43 Sleep.ti,ab.

4442 or 43

45 (babies or baby or boy? or child* or girl? or infan* or kid? or neonat* or neo-nat* or newborn* or new-born* or paediatric* or peadiatric* or pediatric* or perinat* or toddler?).ti,ab.

46 (pregnan* or perinatal* or prenatal* or antenatal or postnatal*).ti,ab.

47 Parents/

48 (parent\$ or care giver or caregiver or guardian or family or families or mother\$ or father\$ or maternal or paternal).tw.

4945 or 46 or 47 or 48

5026 or 33 or 41 or 44

$51 \quad 16$ and 50

5249 and 51

53 (exp animals/ not humans.sh.) or (rat or rats or mouse or mice or rodent*).ti.

5452 not 53

55 exp experimental design/

56 randomi\#ed.ti,ab.

57 randomly.ab.

58 exp clinical trials/

59 trial.ti.

60 exp randomized controlled trial/ 


\begin{tabular}{|l|l|}
\hline 61 & 55 or 56 or 57 or 58 or 60 \\
\hline 62 & 54 and 61 \\
\hline 63 & limit 62 to $y r=" 2020-2021 "$ \\
\hline
\end{tabular}

\section{WHO ICTRP}

\begin{tabular}{|l|}
\hline Basic search \\
\hline 1. $\quad$ babies AND obesity \\
\hline 2. $\quad$ babies AND obese \\
\hline 3. $\quad$ babies AND overweight \\
\hline 4. $\quad$ infant AND obesity \\
\hline 5. $\quad$ infant AND obese \\
\hline 6. $\quad$ infant AND overweight \\
\hline 7. $\quad$ infants AND obesity \\
\hline 8. $\quad$ infants AND obese \\
\hline 9. infants AND overweight \\
\hline 10. child AND obesity \\
\hline 11. child AND obese \\
\hline 12. child AND overweight \\
\hline 13. children AND obesity \\
\hline 14. children AND obese \\
\hline 15. children AND overweight \\
\hline 16. childhood AND obesity \\
\hline 17. childhood AND obese \\
\hline 18. childhood AND overweight \\
\hline 19. pediatric AND obesity \\
\hline 20. paediatric AND obesity \\
\hline 21. pediatric AND obese \\
\hline 22. paediatric AND obese \\
\hline 23. pediatric AND overweight \\
\hline 24. paediatric AND overweight \\
\hline 25. toddler AND obesity \\
\hline 26. toddler AND obese \\
\hline 27. toddler AND overweight \\
\hline 28. toddlers AND obesity \\
\hline 29. toddlers AND obese \\
\hline 30. toddlers AND overweight \\
\hline 31. kids AND obesity \\
\hline 32. kids AND obese \\
\hline 33. kids AND overweight \\
\hline
\end{tabular}

\section{Clinicaltrials.gov}

Advanced search

Condition or disease: overweight OR obesity OR obese OR adiposity OR BMI OR weight gain

Other Terms: baby OR infant OR child OR paediatric OR pediatric OR toddler OR offspring 


\section{TOPCH§̊LD}

Supplementary file 3: Eligible randomised controlled trials for the Transforming Obesity Prevention for Children (TOPCHILD) Collaboration

This table shows all trials that we have identified up to March 2021 as being eligible for inclusion in TOPCHILD. Trials marked in blue have already agreed to join the Collaboration and share their data and unpublished intervention materials.

\begin{tabular}{|c|c|c|c|c|c|c|c|}
\hline Trial Country/ies (PI) & $\begin{array}{l}\text { Registration number } \\
\text { (registration year) }\end{array}$ & $\begin{array}{l}\text { Protocol } \\
\text { publication } \\
\text { year }\end{array}$ & $\begin{array}{l}\text { Main } \\
\text { results } \\
\text { publication } \\
\text { year }\end{array}$ & $\begin{array}{l}\text { Start year/ } \\
\text { completion } \\
\text { year }\end{array}$ & $\begin{array}{l}\text { Sample } \\
\text { size }\end{array}$ & Participants & Primary outcome/s \\
\hline $\begin{array}{l}\text { Australia } \\
\text { (Campbell) }^{1}\end{array}$ & $\begin{array}{l}\text { ISRCTN81847050² } \\
(2008)\end{array}$ & $2008^{3}$ & $2013^{1}$ & $2008 / 2010$ & 542 & $\begin{array}{l}\text { First-time parent regularly } \\
\text { attending first-time parent group }\end{array}$ & Dietary intake \\
\hline $\begin{array}{l}\text { Australia } \\
\text { (Campbell) }^{4}\end{array}$ & $\begin{array}{l}\text { ACTRN126110003869325 } \\
(2011)\end{array}$ & $2016^{4}$ & na & $2011 / 2020$ & 560 & $\begin{array}{l}\text { First-time parent groups with } \\
\text { children aged 3-4 months }\end{array}$ & $\begin{array}{l}\text { Anthropometry: height, weight, } \\
\text { waist circumference, BMI z-score } \\
\text { at } 18 \text { and } 36 \text { months of age }\end{array}$ \\
\hline $\begin{array}{l}\text { Australia } \\
\text { (Daniels) }^{6}\end{array}$ & $\begin{array}{l}\text { ACTRN12608000056392 } \\
(2008)\end{array}$ & $2009^{8}$ & $2013^{6}$ & $2008 / 2009$ & 698 & $\begin{array}{l}\text { First-time mothers of healthy term } \\
\text { infants }\end{array}$ & $\begin{array}{l}\text { Food intake, food preferences, } \\
\text { and feeding behaviour }\end{array}$ \\
\hline $\begin{array}{l}\text { Australia } \\
{\text { (Wen })^{9}}^{9}\end{array}$ & $\begin{array}{l}\text { ACTRN12607000168459 } \\
(2007)\end{array}$ & $2007^{11}$ & $2012^{9}$ & $2007 / 2010$ & 782 & $\begin{array}{l}\text { Women expecting their first child, } \\
\text { between } 24-34 \text { weeks pregnancy }\end{array}$ & $\mathrm{BMI}$ at 2 years of age \\
\hline $\begin{array}{l}\text { Australia } \\
(\text { Wen })^{12}\end{array}$ & $\begin{array}{l}\text { ACTRN12616001470482 } \\
(2016)\end{array}$ & $2019^{14}$ & $2020^{12}$ & $2017 / 2020$ & 1150 & Women in their third trimester & $\begin{array}{l}\text { BMI, breastfeeding duration, and } \\
\text { timing of introduction of solids }\end{array}$ \\
\hline $\begin{array}{l}\text { Belarus } \\
\text { (Oken/Kramer) }^{15}\end{array}$ & $\begin{array}{l}\text { ISRCTN37687716 } \\
(2005) \\
\text { NCT01561612 } \\
(2012)\end{array}$ & na & $2009^{15}$ & $1996 / 1998$ & 17,046 & $\begin{array}{l}\text { Mother-infant pairs consisting of } \\
\text { full-term singleton infants } \\
\text { weighing at least } 2500 \mathrm{~g} \text { and their } \\
\text { healthy mothers who intended to } \\
\text { breastfeed }\end{array}$ & $\begin{array}{l}\text { Duration of any breastfeeding, } \\
\text { prevalence of predominant } \\
\& \text { exclusive breastfeeding at } 3 \& 6 \\
\text { months of life, occurrence of } 1 \text { or } \\
\text { more episodes of gastrointestinal } \\
\text { tract infection, } 2 \text { or more episodes } \\
\text { of respiratory tract infection, and } \\
\text { atopic eczema during the first } 12 \\
\text { months of life }\end{array}$ \\
\hline $\begin{array}{l}\text { Belgium } \\
\text { (Verbestel) }^{18}\end{array}$ & na & na & $2013^{18}$ & $2009 / 2009$ & 203 & $\begin{array}{l}\text { Parents of children aged 9-24 } \\
\text { months }\end{array}$ & $\begin{array}{l}\text { BMI z-score, children's lifestyle } \\
\text { behaviours }\end{array}$ \\
\hline $\begin{array}{l}\text { Brazil } \\
\text { (Vitolo) }^{19}\end{array}$ & $\begin{array}{l}\text { NCT0062962920 } \\
(2008)\end{array}$ & na & $2010^{19}$ & $2001 / 2003$ & 500 & $\begin{array}{l}\text { Newborn infants with birthweight } \\
\geq 2500 \text { g and gestational age } \geq 37 \\
\text { weeks }\end{array}$ & $\begin{array}{l}\text { Exclusive breastfeeding at } 1 \text { year, } \\
\text { lipid profile at } 7-8 \text { years of age }\end{array}$ \\
\hline $\begin{array}{l}\text { Brazil } \\
\text { (Vitolo) }^{21}\end{array}$ & $\begin{array}{l}\text { NCT0063545322 } \\
(2008)\end{array}$ & na & $2019^{21}$ & $2008 / 2010$ & 715 & $\begin{array}{l}\text { Pregnant women in their third } \\
\text { trimester }\end{array}$ & $\begin{array}{l}\text { Exclusive breastfeeding at } 4 \\
\text { months }\end{array}$ \\
\hline
\end{tabular}




\section{TOPCH§̊LD}

\begin{tabular}{|c|c|c|c|c|c|c|c|}
\hline Trial Country/ies (PI) & $\begin{array}{l}\text { Registration number } \\
\text { (registration year) }\end{array}$ & $\begin{array}{l}\text { Protocol } \\
\text { publication } \\
\text { year }\end{array}$ & $\begin{array}{l}\text { Main } \\
\text { results } \\
\text { publication } \\
\text { year }\end{array}$ & $\begin{array}{l}\text { Start year/ } \\
\text { completion } \\
\text { year }\end{array}$ & $\begin{array}{l}\text { Sample } \\
\text { size }\end{array}$ & Participants & Primary outcome/s \\
\hline $\begin{array}{l}\text { Canada } \\
\text { (Dennis) }{ }^{23}\end{array}$ & $\begin{array}{l}\text { ISRCTN13308752 } \\
\text { (2019) }\end{array}$ & $2021^{23}$ & na & $2019 / 2022$ & 5230 & $\begin{array}{l}\text { Non-pregnant mother with no } \\
\text { child or one child between 3-12 } \\
\text { months }\end{array}$ & $\begin{array}{l}\text { Proportion of infants with a } \\
\text { BMI>85 percentile using World } \\
\text { Health Organization growth } \\
\text { reference range by sex and } \\
\text { measured at } 5 \text { years of age }\end{array}$ \\
\hline $\begin{array}{l}\text { China } \\
\text { (Huang) }\end{array}$ & $\begin{array}{l}\text { ChiCTR180001777326 } \\
\text { (2018) }\end{array}$ & na & na & $2018 / 2029$ & 4500 & $\begin{array}{l}\text { Women between } 20-42 \text { years of } \\
\text { age, planning pregnancy in the } \\
\text { next } 6 \text { months or }<14 \text { weeks } \\
\text { pregnant, singleton pregnancy }\end{array}$ & $\begin{array}{l}\text { Obesity and overweight at } 5 \text { years } \\
\text { of age }\end{array}$ \\
\hline $\begin{array}{l}\text { China } \\
(X i a)^{27}\end{array}$ & $\begin{array}{l}\text { NCT04661449 } 27 \\
(2020)\end{array}$ & na & na & $2021 / 2023$ & 138 & $\begin{array}{l}\text { Term infants that are large for } \\
\text { gestational age }\end{array}$ & $\begin{array}{l}\text { Rate of overweight/obesity at } 2 \\
\text { years old and } 7 \text { years old }\end{array}$ \\
\hline $\begin{array}{l}\text { Denmark } \\
\text { (Pryds) }^{28}\end{array}$ & $\begin{array}{l}\text { NCT0123566329 } \\
(2010)\end{array}$ & na & $2013^{28}$ & $2010 / 2013$ & 226 & $\begin{array}{l}\text { Obese mothers and healthy } \\
\text { infants born at term (>258 days of } \\
\text { gestation), postnatal age }>48 \mathrm{~h} \text {. } \\
\text { Women who intended to } \\
\text { breastfeed and had participated in } \\
\text { the Treatment of Obese Pregnant } \\
\text { study (TOP-study) }\end{array}$ & $\begin{array}{l}\text { Breastfeeding, infant } \\
\text { anthropometrics at } 6 \text { months of } \\
\text { age }\end{array}$ \\
\hline $\begin{array}{l}\text { Denmark } \\
{\text { (Skovgaard })^{30}}\end{array}$ & $\begin{array}{l}\text { NCT04601779 } \\
(2020)\end{array}$ & na & na & $2023 / 2024$ & 1000 & $\begin{array}{l}\text { Children who have been assessed } \\
\text { as having three or more problems } \\
\text { at age } 9-10 \text { months at assessment }\end{array}$ & $\begin{array}{l}\text { Child mental health at } 24 \text { months, } \\
\text { social and emotional development } \\
\text { at } 24 \text { months }\end{array}$ \\
\hline $\begin{array}{l}\text { Finland } \\
{\text { (Virtanen })^{31}}\end{array}$ & $\begin{array}{l}\text { NCT01204489 } \\
(2010)\end{array}$ & na & na & $2010 / 2012$ & 148 & $\begin{array}{l}\text { all families at their child's standard } \\
\text { 6-month child welfare clinic visit }\end{array}$ & $\begin{array}{l}\text { Changes in family's dietary } \\
\text { choices, knowledge and attitudes } \\
\text { at } 8 \text { months }\end{array}$ \\
\hline $\begin{array}{l}\text { France } \\
\text { (Parat) }^{32}\end{array}$ & $\begin{array}{l}\text { NCT00804765 } \\
\text { (2008) }\end{array}$ & na & $2019^{32}$ & $2008 / 2013$ & 275 & $\begin{array}{l}\text { Women at } \leq 21 \text { gestational weeks } \\
\text { with } \mathrm{BMI}>25 \mathrm{~kg} / \mathrm{m}^{2}\end{array}$ & $\begin{array}{l}\text { Excessive infancy weight gain } \\
\text { defined as }>0.67 \text { change in weight } \\
\text { SD score }\end{array}$ \\
\hline $\begin{array}{l}\text { Guatemala } \\
\text { (Acero) })^{34}\end{array}$ & $\begin{array}{l}\text { NCT0339961735 } \\
(2018)\end{array}$ & $2020^{34}$ & na & $2018 / 2021$ & 1500 & $\begin{array}{l}\text { Women in third trimester or with } \\
\text { children up to } 3 \text { months of age }\end{array}$ & $\begin{array}{l}\text { Infant and young child feeding } \\
\text { practices, height, weight gain rate, } \\
\text { haemoglobin, obesity, stunting, } \\
\text { anaemia }\end{array}$ \\
\hline $\begin{array}{l}\text { India } \\
{\text { (Kumaran) })^{36}}\end{array}$ & $\begin{array}{l}\text { ISRCTN2016147937 } \\
(2020) \\
\text { CTRI/2020/12/03013 }\end{array}$ & $2021^{36}$ & na & $2021 / 2028$ & 6000 & Women of reproductive age & Adiposity at 5 years of age \\
\hline
\end{tabular}




\section{TOPCH§̊LD}

\begin{tabular}{|c|c|c|c|c|c|c|c|}
\hline Trial Country/ies (PI) & $\begin{array}{l}\text { Registration number } \\
\text { (registration year) }\end{array}$ & $\begin{array}{l}\text { Protocol } \\
\text { publication } \\
\text { year }\end{array}$ & $\begin{array}{l}\text { Main } \\
\text { results } \\
\text { publication } \\
\text { year } \\
\end{array}$ & $\begin{array}{l}\text { Start year/ } \\
\text { completion } \\
\text { year }\end{array}$ & $\begin{array}{l}\text { Sample } \\
\text { size }\end{array}$ & Participants & Primary outcome/s \\
\hline & (2020) & & & & & & \\
\hline 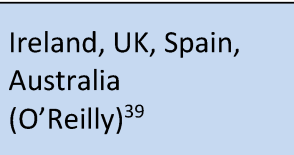 & $\begin{array}{l}\text { ACTRN12620001240932 } 39 \\
(2020)\end{array}$ & na & na & $2021 / 2024$ & 800 & $\begin{array}{l}\text { Pregnant women aged } 18-50 \text { years } \\
\text { at high risk of developing } \\
\text { gestational diabetes }\end{array}$ & $\begin{array}{l}\text { Maternal: BMI at } 12 \text { months } \\
\text { postpartum; Infants: weight, } \\
\text { height, head circumference at age } \\
12 \text { months }\end{array}$ \\
\hline $\begin{array}{l}\text { Italy } \\
\text { (Maffeis) }^{40}\end{array}$ & $\begin{array}{l}\text { NCT03131284 } \\
(2017)\end{array}$ & na & $2019^{40}$ & 2014/2017 & 562 & Healthy full-term newborns & BMI at two years of age \\
\hline $\begin{array}{l}\text { Netherlands } \\
\text { (Corpeleijn) }^{42}\end{array}$ & $\begin{array}{l}\text { NCT01127412 } \\
(2010)\end{array}$ & na & $2014^{42}$ & $2006 / 2010$ & 161 & Infants aged up to 2 weeks & $\begin{array}{l}\text { Growth (weight, length), body } \\
\text { composition (waist circumference, } \\
\text { hip circumference, skinfold } \\
\text { thickness, bioelectrical impedance } \\
\text { analyses) all assessed regularly } \\
\text { during the first } 2.5 \text { years of life }\end{array}$ \\
\hline $\begin{array}{l}\text { Netherlands } \\
\text { (Karssen) }^{44}\end{array}$ & $\begin{array}{l}\text { NL6727/NTR6938 } \\
\text { (2017) }\end{array}$ & $2021^{44}$ & na & 2018/2019 & 300 & $\begin{array}{l}\text { Parents with a child aged 7-11 } \\
\text { months }\end{array}$ & BMI at 6 and 12 months \\
\hline $\begin{array}{l}\text { Netherlands } \\
\text { (Mesman) }^{46}\end{array}$ & $\begin{array}{l}\text { NCT03348176 } \\
(2017) \\
\text { NL6397/NTR6572 } \\
(2017)\end{array}$ & $2019^{46}$ & na & $2016 / 2020$ & 255 & $\begin{array}{l}\text { First-time mothers of healthy term } \\
\text { infants } 4 \text { months to } 3 \text { years of age }\end{array}$ & $\begin{array}{l}\text { Vegetable intake, vegetable liking, } \\
\text { self-regulation of energy intake }\end{array}$ \\
\hline $\begin{array}{l}\text { Netherlands } \\
\text { (Raat) }^{49}\end{array}$ & $\begin{array}{l}\text { NL1721/NTR183150 } \\
(2009)\end{array}$ & $2013^{51}$ & $2017^{49}$ & 2008/2013 & 2102 & $\begin{array}{l}\text { Newborn children and their } \\
\text { parents }\end{array}$ & $\begin{array}{l}\text { BMI and energy-balance related } \\
\text { behaviours }\end{array}$ \\
\hline $\begin{array}{l}\text { New Zealand } \\
(\text { Taylor })^{52}\end{array}$ & $\begin{array}{l}\text { NCTO0892983 } \\
(2009)\end{array}$ & $2011^{54}$ & $2017^{52}$ & 2009/2017 & 802 & $\begin{array}{l}\text { Women aged over } 16 \text { before } 34 \\
\text { weeks' gestation. Babies excluded } \\
\text { if they are not full-term }\end{array}$ & $\begin{array}{l}\text { Weight at } 6,12 \text { and } 24 \text { months of } \\
\text { age; BMl at } 24 \text { months of age }\end{array}$ \\
\hline $\begin{array}{l}\text { New Zealand } \\
\text { (Taylor) }^{55}\end{array}$ & $\begin{array}{l}\text { ACTRN12612001133820 } \\
\text { (2012) }\end{array}$ & $2015^{57}$ & $2017^{55}$ & 2012/2016 & 206 & $\begin{array}{l}\text { Pregnant women aged } 16 \text { or over, } \\
\text { before } 34 \text { weeks' gestation. Babies } \\
\text { excluded if they are not full-term }\end{array}$ & BMI at 12 months \\
\hline $\begin{array}{l}\text { Norway } \\
(\text { Helle })^{58}\end{array}$ & $\begin{array}{l}\text { ISRCTN1360156759 } \\
\text { (2016) }\end{array}$ & $2017^{60}$ & $2019^{58}$ & 2015/2021 & 718 & Parent and 5.5-month-old child & $\begin{array}{l}\text { Child eating behaviour, child food } \\
\text { intake, child mealtime routines, } \\
\text { maternal feeding practices }\end{array}$ \\
\hline $\begin{array}{l}\text { Norway } \\
(\emptyset \text { verby })^{61}\end{array}$ & $\begin{array}{l}\text { ISRCTN45864056 } \\
\text { (2016) }\end{array}$ & na & $2017^{61}$ & 2012/2015 & 110 & Parents and 4-6 month old infant & $\begin{array}{l}\text { Food intake when infants are } 6,15 \\
\text { and } 24 \text { months of age }\end{array}$ \\
\hline
\end{tabular}




\section{TOPCH§̊LD}

\begin{tabular}{|c|c|c|c|c|c|c|c|}
\hline Trial Country/ies (PI) & $\begin{array}{l}\text { Registration number } \\
\text { (registration year) }\end{array}$ & $\begin{array}{l}\text { Protocol } \\
\text { publication } \\
\text { year }\end{array}$ & $\begin{array}{l}\text { Main } \\
\text { results } \\
\text { publication } \\
\text { year }\end{array}$ & $\begin{array}{l}\text { Start year/ } \\
\text { completion } \\
\text { year }\end{array}$ & $\begin{array}{l}\text { Sample } \\
\text { size }\end{array}$ & Participants & Primary outcome/s \\
\hline $\begin{array}{l}\text { Norway } \\
(\text { Røed })^{63}\end{array}$ & $\begin{array}{l}\text { ISRCTN92980420 } \\
\text { (2017) }\end{array}$ & $2019^{63}$ & $2021^{65}$ & 2015/2022 & 298 & $\begin{array}{l}\text { Children close to } 12 \text { months and } \\
\text { one of their parents }\end{array}$ & $\begin{array}{l}\text { Child diet quality and food variety, } \\
\text { assessed at inclusion, 18, 24, and } \\
48 \text { months }\end{array}$ \\
\hline $\begin{array}{l}\text { South Africa } \\
\text { (Norris) }^{66}\end{array}$ & $\begin{array}{l}\text { PACTR201903750173871 } \\
\text { (2019) }\end{array}$ & na & na & $2019 / 2021$ & 6000 & $\begin{array}{l}18-25 \text { year old women } \\
\text { preconception and child }\end{array}$ & $\begin{array}{l}\text { Dual-energy X-ray absorptiometry- } \\
\text { derived fat mass index of the } \\
\text { index-child at age } 5 \text { years }\end{array}$ \\
\hline $\begin{array}{l}\text { Spain } \\
\text { (López) }^{67}\end{array}$ & $\begin{array}{l}\text { NCT03444415 } \\
(2018)\end{array}$ & na & na & $2015 / 2018$ & 414 & $\begin{array}{l}\text { Pregnant women with a } \\
\text { gestational age of } 12-16 \text { weeks }\end{array}$ & BMI at 2 years of age \\
\hline $\begin{array}{l}\text { Sweden } \\
\text { (Marcus) }^{68}\end{array}$ & $\begin{array}{l}\text { NCT01198847 } \\
(2010)\end{array}$ & $2011^{68}$ & na & $2010 / 2019$ & 123 & $\begin{array}{l}\text { At least one obese }(\mathrm{BMI} \geq 30) \text { or } \\
\text { two overweight }(\mathrm{BMI} \geq 25) \\
\text { parents with a one-year-old child }\end{array}$ & BMI at 6 years of age \\
\hline $\begin{array}{l}\text { Sweden } \\
\text { (Rasmussen) }^{70}\end{array}$ & $\begin{array}{l}\text { ISRCTN1699191971 } \\
(2013)\end{array}$ & $2014^{72}$ & $2016^{70}$ & 2008/2015 & 1039 & $\begin{array}{l}\text { First-time mothers and their } \\
\text { children recruited at child health } \\
\text { care centres at } 9-10 \text { months of age }\end{array}$ & $\begin{array}{l}\text { BMI and waist circumference of } \\
\text { children \& their mothers at age } 4\end{array}$ \\
\hline $\begin{array}{l}\text { UK } \\
\text { (Bryant) })^{73}\end{array}$ & $\begin{array}{l}\text { ISRCTN5673542974 } \\
(2013)\end{array}$ & na & $2016^{73}$ & 2012/2012 & 120 & $\begin{array}{l}\text { Overweight/obese pregnant } \\
\text { women (BMI } \geq 25 \text { ) at } 10-12 \text { weeks' } \\
\text { gestation and infants from birth }\end{array}$ & Child's weight \\
\hline $\begin{array}{l}\text { UK } \\
\text { (Bryant) }\end{array}$ & $\begin{array}{l}\text { NCT03333733 } \\
(2017)\end{array}$ & $2018^{77}$ & $2021^{75}$ & 2017/2019 & 115 & $\begin{array}{l}\text { Parents and at least } 1 \text { child aged } 6 \\
\text { months }-5 \text { years }\end{array}$ & Feasibility, child BMI z-score \\
\hline $\begin{array}{l}\text { UK } \\
\text { (Lakshman) })^{78}\end{array}$ & $\begin{array}{l}\text { ISRCTN2081469379 } \\
\text { (2011) }\end{array}$ & $2015^{80}$ & $2018^{78}$ & 2011/2015 & 669 & $\begin{array}{l}\text { Parents (mainly mothers) } \\
\text { and their babies (aged } 2 \text { to } 14 \\
\text { weeks) who are formula-fed }\end{array}$ & $\begin{array}{l}\text { The change in infant weight } \\
\text { standard deviation score from } \\
\text { birth to age } 12 \text { months }\end{array}$ \\
\hline $\begin{array}{l}\text { USA } \\
\text { (Barlow) })^{81}\end{array}$ & $\begin{array}{l}\text { NCT03101943 } \\
(2017)\end{array}$ & na & $2020^{81}$ & 2017/2019 & 134 & $\begin{array}{l}\text { Mothers aged } \geq 13 \text { years, their } \\
\text { infant aged }<14 \text { weeks, self- } \\
\text { reported Native American }\end{array}$ & $\begin{array}{l}\text { Infant consumption of sugar- } \\
\text { sweetened beverages, change in } \\
\text { complementary feeding and } \\
\text { responsive parenting practices }\end{array}$ \\
\hline $\begin{array}{l}\text { USA } \\
(\text { Barlow) }\end{array}$ & $\begin{array}{l}\text { NCT03334266 } \\
\text { (2017) }\end{array}$ & $2019^{83}$ & na & $2017 / 2021$ & 338 & $\begin{array}{l}\text { Expectant Native American } \\
\text { mothers aged } 14-24 \text { who are } \\
\text { having their first or second baby }\end{array}$ & $\begin{array}{l}\text { Percentage of parents who meet } \\
\text { breastfeeding and complementary } \\
\text { feeding recommendations, child } \\
\text { feeding styles, fruit \& vegetable } \\
\text { intake, physical activity levels, } \\
\text { screen time, BMI }\end{array}$ \\
\hline
\end{tabular}




\section{TOPCH§̊LD}

\begin{tabular}{|c|c|c|c|c|c|c|c|}
\hline Trial Country/ies (PI) & $\begin{array}{l}\text { Registration number } \\
\text { (registration year) }\end{array}$ & $\begin{array}{l}\text { Protocol } \\
\text { publication } \\
\text { year }\end{array}$ & $\begin{array}{l}\text { Main } \\
\text { results } \\
\text { publication } \\
\text { year }\end{array}$ & $\begin{array}{l}\text { Start year/ } \\
\text { completion } \\
\text { year }\end{array}$ & $\begin{array}{l}\text { Sample } \\
\text { size }\end{array}$ & Participants & Primary outcome/s \\
\hline $\begin{array}{l}\text { USA } \\
(\text { Beck) }\end{array}$ & $\begin{array}{l}\text { NCT022572038 } \\
(2014)\end{array}$ & na & $2017^{85}$ & 2014/2015 & 82 & $\begin{array}{l}\text { Parents self-identify as Latino and } \\
\text { have a child between the ages of } 6 \\
\text { months and } 5 \text { years }\end{array}$ & $\begin{array}{l}\text { Proportion of parents reporting } \\
\text { that their child had consumed a } \\
\text { sugar-sweetened beverage on the } \\
\text { day prior at a 2-week follow up }\end{array}$ \\
\hline $\begin{array}{l}\text { USA } \\
(\text { Beck) }\end{array}$ & $\begin{array}{l}\text { NCT03438721 } \\
(2018)\end{array}$ & na & na & $2018 / 2021$ & 240 & $\begin{array}{l}\text { Parents who self-identify as Latino } \\
\text { and their newborn infants }\end{array}$ & $\begin{array}{l}\text { Child dietary intake and screen } \\
\text { time, parent health-related quality } \\
\text { of life }\end{array}$ \\
\hline $\begin{array}{l}\text { USA } \\
(\text { Birch/Paul })^{88}\end{array}$ & $\begin{array}{l}\text { NCTO0359242 } \\
(2006)\end{array}$ & na & $2011^{88}$ & $2006 / 2009$ & 160 & $\begin{array}{l}\text { Mother-newborn dyads, } \\
\text { primiparous, singleton, gestational } \\
\text { age } \geq 34 \text { weeks }\end{array}$ & $\begin{array}{l}\text { Weight-for-length percentile at } \\
\text { age } 1 \text { year }\end{array}$ \\
\hline $\begin{array}{l}\text { USA } \\
(\text { Bonuck })^{90}\end{array}$ & $\begin{array}{l}\text { NCT00756626 } \\
(2008)\end{array}$ & na & $2014^{90}$ & $2008 / 2011$ & 300 & $\begin{array}{l}\text { Children } 11-13 \text { months old } \\
\text { consuming }>2 \text { bottles of milk or } \\
\text { juice per day }\end{array}$ & Bottle use frequency \\
\hline $\begin{array}{l}\text { USA } \\
\text { (Caballero) }\end{array}$ & na & na & $2015^{92}$ & na/na & 292 & $\begin{array}{l}\text { Healthy newborns with } \geq 2000 \mathrm{~g} \\
\text { body weight }\end{array}$ & $\begin{array}{l}\text { Anthropometry (weight, height, } \\
\text { triceps, and subscapular } \\
\text { skinfolds), child feeding practices } \\
\text { and dietary assessment }\end{array}$ \\
\hline $\begin{array}{l}\text { USA (Puerto Rico) } \\
\text { (Campos) }^{93}\end{array}$ & $\begin{array}{l}\text { NCT0351789194 } \\
(2018)\end{array}$ & $2020^{93}$ & na & 2018/2022 & 480 & $\begin{array}{l}\text { Low-income women in third } \\
\text { trimester, intend to participate in } \\
\text { the Special Nutrition Women, } \\
\text { Infants \& Children Program; } \\
\text { infants included from birth }\end{array}$ & $\begin{array}{l}\text { Adequate weight gain during the } \\
\text { first year (gender adjusted Z } \\
\text { score). }\end{array}$ \\
\hline $\begin{array}{l}\text { USA } \\
\text { (Clouiter) }^{95}\end{array}$ & $\begin{array}{l}\text { NCT02052518 } \\
\text { (2014) }\end{array}$ & $2015^{97}$ & $2018^{95}$ & $2013 / 2016$ & 57 & $\begin{array}{l}\text { Mother/newborn dyads in low- } \\
\text { income neighbourhoods }\end{array}$ & $\begin{array}{l}\text { Breastfeeding, Infant weight-for- } \\
\text { length, BMI, introduction of solids } \\
\text { and juice/sugar-sweetened } \\
\text { beverages }\end{array}$ \\
\hline $\begin{array}{l}\text { USA } \\
\text { (de la Haye) }^{98}\end{array}$ & na & na & $2019^{98}$ & na & 50 & $\begin{array}{l}\text { Mother-infant dyads receiving } \\
\text { home visiting program (HVP) }\end{array}$ & $\begin{array}{l}\text { Feasibility, mother BMI, infant } \\
\text { weight-for-length z-score, mother } \\
\text { and infant diet, mother physical } \\
\text { activity }\end{array}$ \\
\hline $\begin{array}{l}\text { USA } \\
\text { (de la Haye \& Salvy) })^{99}\end{array}$ & $\begin{array}{l}\text { NCT03529695 } 5^{100} \\
(2018)\end{array}$ & $2019^{99}$ & na & 2018/2022 & 300 & $\begin{array}{l}\text { Mother-child dyads enrolled in } \\
\text { home visitation programs; Infants } \\
\text { aged between birth to } 24 \text { months }\end{array}$ & $\begin{array}{l}\text { Weight of mothers, rate of weight } \\
\text { gain of infants, waist } \\
\text { circumference of mother }\end{array}$ \\
\hline
\end{tabular}




\section{TOPCH§̊LD}

\begin{tabular}{|c|c|c|c|c|c|c|c|}
\hline Trial Country/ies (PI) & $\begin{array}{l}\text { Registration number } \\
\text { (registration year) }\end{array}$ & $\begin{array}{l}\text { Protocol } \\
\text { publication } \\
\text { year }\end{array}$ & $\begin{array}{l}\text { Main } \\
\text { results } \\
\text { publication } \\
\text { year }\end{array}$ & $\begin{array}{l}\text { Start year/ } \\
\text { completion } \\
\text { year }\end{array}$ & $\begin{array}{l}\text { Sample } \\
\text { size }\end{array}$ & Participants & Primary outcome/s \\
\hline $\begin{array}{l}\text { USA } \\
\text { (Fiks) }^{101}\end{array}$ & $\begin{array}{l}\text { NCT02037490 } \\
(2014)\end{array}$ & na & $2017^{101}$ & $2014 / 2015$ & 87 & $\begin{array}{l}\text { Pregnant women, Medicaid } \\
\text { insured, } \mathrm{BMI} \geq 25\end{array}$ & Feasibility \\
\hline $\begin{array}{l}\text { USA } \\
\text { (Gesell) }^{103}\end{array}$ & $\begin{array}{l}\text { NCT01081340 } \\
(2010)\end{array}$ & na & na & $2010 / 2011$ & 41 & $\begin{array}{l}\text { Latina women who are less than } \\
24 \text { weeks pregnant, have not } \\
\text { carried a pregnancy to term, have } \\
\text { not had a termination of a } \\
\text { previous pregnancy prior to } 20 \\
\text { weeks }\end{array}$ & $\begin{array}{l}\text { Gestational weight gain and } \\
\text { postpartum weight loss }\end{array}$ \\
\hline 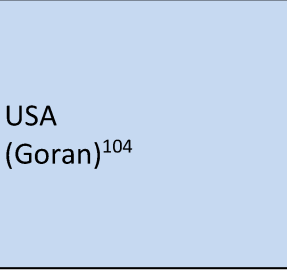 & $\begin{array}{l}\text { NCT03141346 } \\
\text { (2017) }\end{array}$ & na & na & $2017 / 2022$ & 240 & $\begin{array}{l}\text { Latina mothers who are habitual } \\
\text { consumers of sugar sweetened } \\
\text { beverages/juices and singleton } \\
\text { infants less than one month }\end{array}$ & $\begin{array}{l}\text { infant length, maternal height, } \\
\text { maternal weight, maternal BMI, } \\
\text { infant weight, infant weight z- } \\
\text { scores, infant body composition } \\
\text { (body fat, lean mass, total body } \\
\text { water, free body water) at } 6,12 \\
\text { and } 24 \text { months }\end{array}$ \\
\hline $\begin{array}{l}\text { USA } \\
\text { (Groner) }\end{array}$ & $\begin{array}{l}\text { NCT01565525 } \\
(2012)\end{array}$ & $2009^{107}$ & $2012^{105}$ & $2005 / 2007$ & 292 & $\begin{array}{l}\text { Mother-infant dyads were } \\
\text { enrolled at their first well-child } \\
\text { visit to } 3 \text { urban paediatric clinics }\end{array}$ & Infant weight for height \\
\hline $\begin{array}{l}\text { USA } \\
\text { (Hodges) }^{108}\end{array}$ & $\begin{array}{l}\text { NCT04502979108 } \\
(2020)\end{array}$ & na & na & 2017/2019 & 71 & $\begin{array}{l}\text { Parents must be able to read and } \\
\text { write English or Spanish and } \\
\text { infants must be at least } 3 \text { months } \\
\text { of age at time of recruitment }\end{array}$ & $\begin{array}{l}\text { Infant weight for length z-score at } \\
6 \text { months }\end{array}$ \\
\hline $\begin{array}{l}\text { USA } \\
\text { (Horodynski) }^{109}\end{array}$ & $\begin{array}{l}\text { ACTRN12610000415000 } \\
(2010)\end{array}$ & $2011^{111}$ & $2017^{109}$ & $2010 / 2013$ & 547 & $\begin{array}{l}\text { Economically and educationally } \\
\text { disadvantaged African American, } \\
\text { Hispanic, and Caucasian mothers } \\
\text { with infant } \leq 4 \text { months of age }\end{array}$ & $\begin{array}{l}\text { Maternal responsiveness, } \\
\text { maternal feeding style, maternal } \\
\text { feeding practices, infant growth } \\
\text { pattern at } 6 \text { and } 12 \text { months of age }\end{array}$ \\
\hline $\begin{array}{l}\text { USA } \\
\text { (Horodynski) }^{112}\end{array}$ & $\begin{array}{l}\text { NCT02244424 } \\
\text { (2014) }\end{array}$ & $2015^{112}$ & na & $2014 / 2016$ & 164 & $\begin{array}{l}\text { Low-income adolescent (aged 14- } \\
19 \text { years), first-time mothers of } \\
\text { infants } \leq 2 \text { months of age }\end{array}$ & $\begin{array}{l}\text { Maternal responsiveness, } \\
\text { maternal feeding style, maternal } \\
\text { feeding practices, infant weight }\end{array}$ \\
\hline $\begin{array}{l}\text { USA (Puerto Rico) } \\
\text { (Joshipura) }^{114}\end{array}$ & $\begin{array}{l}\text { NCT01771133 } \\
\text { (2013) }\end{array}$ & na & $2019^{114}$ & $2013 / 2015$ & 31 & $\begin{array}{l}\text { Overweight/obese women with a } \\
\text { singleton pregnancy }<16 \text { weeks' } \\
\text { gestation and their infant from } \\
\text { birth }\end{array}$ & Gestational weight gain \\
\hline
\end{tabular}




\section{TOPCH§̊LD}

\begin{tabular}{|c|c|c|c|c|c|c|c|}
\hline Trial Country/ies (PI) & $\begin{array}{l}\text { Registration number } \\
\text { (registration year) }\end{array}$ & $\begin{array}{l}\text { Protocol } \\
\text { publication } \\
\text { year }\end{array}$ & $\begin{array}{l}\text { Main } \\
\text { results } \\
\text { publication } \\
\text { year }\end{array}$ & $\begin{array}{l}\text { Start year/ } \\
\text { completion } \\
\text { year }\end{array}$ & $\begin{array}{l}\text { Sample } \\
\text { size }\end{array}$ & Participants & Primary outcome/s \\
\hline $\begin{array}{l}\text { USA } \\
\text { (Karasz) }^{116}\end{array}$ & $\begin{array}{l}\text { NCT03077425 } 117 \\
\text { (2017) }\end{array}$ & $2018^{116}$ & na & $2017 / 2021$ & 360 & $\begin{array}{l}\text { Mother-child dyads where child is } \\
<6 \text { months old }\end{array}$ & $\begin{array}{l}\text { Number and amount of sippy cups } \\
\text { and bottles per day consumed by } \\
\text { child }\end{array}$ \\
\hline $\begin{array}{l}\text { USA } \\
(\text { Lavner })^{118}\end{array}$ & $\begin{array}{l}\text { NCT03505203 } \\
(2018)\end{array}$ & $2019^{118}$ & na & $2018 / 2021$ & 300 & $\begin{array}{l}\text { First-time African American } \\
\text { mothers and their full-term } \\
\text { infants }\end{array}$ & $\begin{array}{l}\text { Change in infants' weight for age } \\
\text { from } 3 \text { weeks to } 16 \text { weeks }\end{array}$ \\
\hline $\begin{array}{l}\text { USA } \\
\text { (Linares) })^{120}\end{array}$ & $\begin{array}{l}\text { NCT03903146 } 121 \\
(2019)\end{array}$ & na & $2019^{120}$ & $2016 / 2018$ & 39 & $\begin{array}{l}\text { Hispanic pregnant women who } \\
\text { intended to breastfeed and their } \\
\text { baby }\end{array}$ & $\begin{array}{l}\text { Exclusive breastfeeding from birth } \\
\text { to } 6 \text { months old }\end{array}$ \\
\hline $\begin{array}{l}\text { USA } \\
\text { (Messito) }{ }^{122}\end{array}$ & $\begin{array}{l}\text { NCT01541761 } \\
\text { (2012) }\end{array}$ & na & $2016^{122}$ & $2012 / 2020$ & 533 & $\begin{array}{l}\text { Pregnant women with a singleton } \\
\text { uncomplicated pregnancy }\end{array}$ & $\begin{array}{l}\text { Infant feeding practices and } \\
\text { material infant feeding knowledge }\end{array}$ \\
\hline $\begin{array}{l}\text { USA (Puerto Rico, } \\
\text { Hawaii) } \\
\text { (Palacios) }^{124}\end{array}$ & $\begin{array}{l}\text { NCT02903186 } \\
(2016)\end{array}$ & $2017^{126}$ & $2018^{124}$ & 2016/2016 & 202 & $\begin{array}{l}\text { Caregivers of healthy term infants } \\
0-2 \text { months participating in the } \\
\text { Women, Infants and Children } \\
\text { Program }\end{array}$ & Infant weight-for-length percentile \\
\hline $\begin{array}{l}\text { USA } \\
(\text { Paul })^{127}\end{array}$ & $\begin{array}{l}\text { NCT00125580 } \\
(2005)\end{array}$ & na & na & $2005 / 2006$ & 40 & $\begin{array}{l}\text { Infant at } \geq 37 \text { weeks' gestation, } \\
\text { primiparous mother, singleton, } \\
\text { breast or bottle-fed, birth weight } \\
\geq 2500 \mathrm{~g}\end{array}$ & $\begin{array}{l}\text { The rate of sleeping through the } \\
\text { night at } 8 \text { weeks of age }\end{array}$ \\
\hline $\begin{array}{l}\text { USA } \\
(\text { Paul) }\end{array}$ & $\begin{array}{l}\text { NCT01167270 } \\
(2010) \\
\text { NCT03555331 } \\
(2018)\end{array}$ & $2014^{131}$ & $2018^{128}$ & $2012 / 2023$ & 316 & $\begin{array}{l}\text { Full term singleton infants born to } \\
\text { primiparous mothers }\end{array}$ & BMI z-score at age 3 years \\
\hline $\begin{array}{l}\text { USA } \\
{\text { (Reifsnider) })^{132}}\end{array}$ & $\begin{array}{l}\text { NCT01905072 } \\
(2013)\end{array}$ & $2013^{134}$ & $2018^{132}$ & 2012/2017 & 177 & $\begin{array}{l}\text { Mexican American mother, pre- } \\
\text { pregnant BMI } \geq 25 \text {, aged 18-40 } \\
\text { years; Singleton infants, }>38 \\
\text { weeks' gestational age, } \\
\text { birthweight }>2500 \mathrm{~g}\end{array}$ & $\begin{array}{l}\text { Child weight-for-length BMI at } 3 \\
\text { years }\end{array}$ \\
\hline $\begin{array}{l}\text { USA } \\
\text { (Rothman \& Perrin) }^{135}\end{array}$ & $\begin{array}{l}\text { NCT01040897 } \\
\text { (2009) }\end{array}$ & na & $2021^{135}$ & $2010 / 2014$ & 865 & $\begin{array}{l}\text { Child presenting for } 2 \text { month well- } \\
\text { child check-up (between 6-16 } \\
\text { weeks of age) with an } \\
\text { intervention-trained resident } \\
\text { physician, caregiver able to speak } \\
\text { Spanish or English }\end{array}$ & $\begin{array}{l}\text { Percent of children overweight or } \\
\text { obese at } 2 \text { years }\end{array}$ \\
\hline
\end{tabular}




\section{TOPCH§̊LD}

\begin{tabular}{|c|c|c|c|c|c|c|c|}
\hline Trial Country/ies (PI) & $\begin{array}{l}\text { Registration number } \\
\text { (registration year) }\end{array}$ & $\begin{array}{l}\text { Protocol } \\
\text { publication } \\
\text { year }\end{array}$ & $\begin{array}{l}\text { Main } \\
\text { results } \\
\text { publication } \\
\text { year }\end{array}$ & $\begin{array}{l}\text { Start year/ } \\
\text { completion } \\
\text { year }\end{array}$ & $\begin{array}{l}\text { Sample } \\
\text { size }\end{array}$ & Participants & Primary outcome/s \\
\hline $\begin{array}{l}\text { USA } \\
\text { (Dutton \& Salvy) }^{137}\end{array}$ & $\begin{array}{l}\text { NCT03433456 } \\
(2018)\end{array}$ & $2018^{137}$ & na & $2018 / 2022$ & 596 & $\begin{array}{l}\text { Mother or caregiver and 0-4 year } \\
\text { old child }\end{array}$ & $\begin{array}{l}\text { Change in mother and infants' } \\
\text { body weight from baseline to } \\
\text { follow-up at } 12 \text { and } 24 \text { months }\end{array}$ \\
\hline $\begin{array}{l}\text { USA } \\
\text { (Savage) })^{139}\end{array}$ & $\begin{array}{l}\text { NCT03482908 } \\
(2018)\end{array}$ & $2018^{139}$ & na & $2016 / 2019$ & 289 & $\begin{array}{l}\text { Mother and infant }<2 \text { months, } \\
\text { birthweight } \geq 2500 \mathrm{~g} \text { and } \\
\text { gestational age } \geq 37 \text { weeks }\end{array}$ & $\begin{array}{l}\text { Sex-specific z-scores for infant } \\
\text { growth measures at birth, and at } \\
2,5 \text { and } 7 \text { months after birth; Sex- } \\
\text { specific z-scores for infant rapid } \\
\text { weight gain from birth to } 6 \\
\text { months }\end{array}$ \\
\hline $\begin{array}{l}\text { USA } \\
\text { (Stephens) }^{141}\end{array}$ & $\begin{array}{l}\text { NCT03249324 } \\
(2017)\end{array}$ & $2015^{141}$ & na & $2014 / 2017$ & 58 & $\begin{array}{l}\text { Mothers } 18-35 \text { years of age who } \\
\text { are eligible for care within the } \\
\text { Military Health System; Infants } \\
\text { from birth }\end{array}$ & Maternal weight gain \\
\hline $\begin{array}{l}\text { USA } \\
\text { (Stough) }^{143}\end{array}$ & $\begin{array}{l}\text { NCT03597061 } \\
(2018)\end{array}$ & na & na & $2018 / 2020$ & 34 & $\begin{array}{l}\text { Parent and infant born }>38 \\
\text { weeks' gestation, above } 10^{\text {th }} \\
\text { percentile of length-for-weight, } \\
\text { aged } 2-3 \text { months }\end{array}$ & $\begin{array}{l}\text { Weight-for-Length percentile, } \\
\text { appetite regulation, fruit and } \\
\text { vegetable variety at } 3 \text { and } 9 \\
\text { months of age }\end{array}$ \\
\hline $\begin{array}{l}\text { USA } \\
\text { (Taveras) }^{144}\end{array}$ & $\begin{array}{l}\text { NCT04477577 } \\
(2020)\end{array}$ & $2021^{144}$ & na & $2020 / 2022$ & 500 & $\begin{array}{l}\text { Parental dyads planned } \\
\text { involvement for first year of life, } \\
\text { singleton pregnancy, first child for } \\
\text { both parents, lives within } 25 \mathrm{~km} \\
\text { radius of Boston, and planning to } \\
\text { receive post-partum and pediatric } \\
\text { care for child at any pediatric } \\
\text { practice within the MassGeneral } \\
\text { Brigham (Partners) Healthcare } \\
\text { system }\end{array}$ & $\begin{array}{l}\text { Weight-for-Length z-score at } 6 \text { and } \\
12 \text { months, Weight-for-Length } \geq \\
97.7 \text { percentile at } 12 \text { months, and } \\
\text { Weight-for-Length } \geq 95 \text { percentile } \\
\text { at } 12 \text { months }\end{array}$ \\
\hline $\begin{array}{l}\text { USA } \\
\text { (Thomas) }^{146}\end{array}$ & $\begin{array}{l}\text { NCT03601299 } \\
(2018)\end{array}$ & na & na & $2018 / 2022$ & 804 & Children $0-5$ years of age & $\mathrm{BMI}$, traditional food content \\
\hline $\begin{array}{l}\text { USA } \\
\text { (Thomson) })^{147}\end{array}$ & $\begin{array}{l}\text { NCT01746394 } \\
(2012)\end{array}$ & $2014^{149}$ & $2018^{147}$ & $2013 / 2016$ & 82 & $\begin{array}{l}\text { Pregnant women at least } 18 \text { years } \\
\text { of age, }<19 \text { weeks pregnant and } \\
\text { their infant from birth }\end{array}$ & $\begin{array}{l}\text { Maternal: weight gain at } 9 \\
\text { months' gestation, weight } \\
\text { retention at } 12 \text { months } \\
\text { postpartum, dietary intake, } \\
\text { physical activity; Infant: dietary }\end{array}$ \\
\hline
\end{tabular}




\section{TOPCH§̊LD}

\begin{tabular}{|c|c|c|c|c|c|c|c|}
\hline Trial Country/ies (PI) & $\begin{array}{l}\text { Registration number } \\
\text { (registration year) }\end{array}$ & $\begin{array}{l}\text { Protocol } \\
\text { publication } \\
\text { year }\end{array}$ & $\begin{array}{l}\text { Main } \\
\text { results } \\
\text { publication } \\
\text { year }\end{array}$ & $\begin{array}{l}\text { Start year/ } \\
\text { completion } \\
\text { year }\end{array}$ & $\begin{array}{l}\text { Sample } \\
\text { size }\end{array}$ & Participants & Primary outcome/s \\
\hline & & & & & & & $\begin{array}{l}\text { intake, activity, BMI at age } 12 \\
\text { months }\end{array}$ \\
\hline $\begin{array}{l}\text { USA } \\
\text { (Virudachalam) }{ }^{150}\end{array}$ & $\begin{array}{l}\text { NCT01710423 } \\
(2012)\end{array}$ & na & na & 2012/2013 & 47 & Families with children ages 0 to 3 & Change in healthfulness of the diet \\
\hline $\begin{array}{l}\text { USA } \\
\text { (Wasser) }^{151}\end{array}$ & $\begin{array}{l}\text { NCT01938118 } \\
(2013)\end{array}$ & $2017^{153}$ & $2020^{151}$ & 2013/2017 & 430 & $\begin{array}{l}\text { Non-Hispanic black mothers } \\
\text { enrolled at } 28 \text { weeks' pregnancy } \\
\text { and infants from birth to } 15 \\
\text { months postpartum }\end{array}$ & $\begin{array}{l}\text { Infants' mean weight-for-length z- } \\
\text { score at } 15 \text { months of age }\end{array}$ \\
\hline $\begin{array}{l}\text { USA } \\
\text { (Widen) }^{154}\end{array}$ & $\begin{array}{l}\text { NCTO4177472 } \\
\text { (2019) }\end{array}$ & na & na & 2019/2023 & 150 & $\begin{array}{l}\text { Mothers and assisting caregivers } \\
\text { with babies } 4-5 \text { months of age }\end{array}$ & $\begin{array}{l}\text { BMI percentile at } 12 \text { months of } \\
\text { age }\end{array}$ \\
\hline
\end{tabular}

$\mathrm{na}=$ not available, $\mathrm{BMI}=$ body mass index 


\section{TOPCH§̊LD}

\section{References}

1. Campbell KJ, Lioret S, McNaughton SA, et al. A parent-focused intervention to reduce infant obesity risk behaviors: a randomized trial. Pediatrics 2013;131(4):652-60.

2. ISRTCN Registry. The Infant Feeding Activity and Nutrition Trial (INFANT) an early intervention to prevent childhood obesity: cluster-randomised controlled trial. https://wwwisrctncom/ISRCTN81847050, accessed April 15, 20212008

3. Campbell K, Hesketh K, Crawford D, et al. The Infant Feeding Activity and Nutrition Trial (INFANT) an early intervention to prevent childhood obesity: cluster-randomised controlled trial. BMC public health 2008;8(1):103.

4. Campbell KJ, Hesketh KD, McNaughton SA, et al. The extended Infant Feeding, Activity and Nutrition Trial (InFANT Extend) Program: a cluster-randomized controlled trial of an early intervention to prevent childhood obesity. BMC Public Health 2016;16(1):1-10.

5. ANZCTR Registry. Preventing childhood overweight by promoting healthy lifestyle behaviours from infancy - The extended Infant feeding, activity and nutrition trial. (InFANT Extend). http://wwwanzctrorgau/Trial/Registration/TrialReviewaspx?id=336684\&isReview=true, accessed April 15, 2021 2011

6. Daniels LA, Mallan KM, Nicholson JM, et al. Outcomes of an early feeding practices intervention to prevent childhood obesity. Pediatrics 2013;132(1):e109-e18.

7. ANZCTR Registry. Positive feeding practices and food preferences in very early childhood: an innovative approach to obesity prevention. http://wwwanzctrorgau/Trial/Registration/TrialReviewaspx?id=82533\&isReview=true, accessed April 15, 20212008

8. Daniels LA, Magarey A, Battistutta D, et al. The NOURISH randomised control trial: positive feeding practices and food preferences in early childhood-a primary prevention program for childhood obesity. BMC Public Health 2009;9(1):1-10.

9. Wen LM, Baur LA, Simpson JM, et al. Effectiveness of home based early intervention on children's BMI at age 2: randomised controlled trial. BMJ 2012;344:e3732. doi: 10.1136/bmj.e3732

10. ANZCTR Registry. Early intervention of multiple home visits to prevent childhood obesity among a disadvantaged population: a home-based Randomised Controlled Trial. http://wwwanzctrorgau/Trial/Registration/TrialReviewaspx?id=81895\&isReview=true, accessed April 15, 20212007

11. Wen LM, Baur LA, Rissel C, et al. Early intervention of multiple home visits to prevent childhood obesity in a disadvantaged population: a home-based randomised controlled trial (Healthy Beginnings Trial). BMC Public Health 2007;7(1):76.

12. Wen LM, Rissel C, Xu H, et al. Effects of Telephone and Short Message Service Support on Infant Feeding Practices, "Tummy Time," and Screen Time at 6 and 12 Months of Child Age: A 3-Group Randomized Clinical Trial. JAMA Pediatrics 2020;174(7):657-64. doi: 10.1001/jamapediatrics.2020.0215

13. ANZCTR Registry. Translating research evidence from the Healthy Beginnings Trial to prevent childhood obesity at the beginning of life: feasibility, effectiveness and cost-effectiveness. http://wwwanzctrorgau/Trial/Registration/TrialReviewaspx?id=371401\&isReview=true, accessed April 15, 20212016

14. Wen LM, Rissel C, $\mathrm{Xu} \mathrm{H}$, et al. Linking two randomised controlled trials for Healthy Beginnings $\odot$ : optimising early obesity prevention programs for children under 3 years. BMC Public Health 2019;19(1):1-10.

15. Kramer MS, Matush L, Vanilovich I, et al. A randomized breast-feeding promotion intervention did not reduce child obesity in Belarus. The Journal of nutrition 2009;139(2):417S-21S.

16. ISRTCN Registry. PROmotion of Breastfeeding Intervention Trial. https://wwwisrctncom/ISRCTN37687716, accessed April 15, 20212005 


\section{TOPCHஜ̊LD}

17. Registry Cg. Promotion of Breastfeeding Intervention Trial (PROBIT). https://clinicaltrialsgov/ct2/show/NCT01561612, accessed April 15, 20212012

18. Verbestel V, De Coen V, Van Winckel M, et al. Prevention of overweight in children younger than 2 years old: a pilot cluster-randomized controlled trial. Public health nutrition 2014;17(6):1384-92.

19. Louzada M, Campagnolo P, Rauber F, et al. Long-term Effectiveness of Maternal Dietary Counseling in a Low-Income Population: A Randomized Field Trial. Pediatrics 2012;129(6):e1477-e84. doi: 10.1542/peds.2011-3063

20. Registry Cg. Impacts of the 10 Steps for Healthy Feeding in Infants: a Randomized Field Trial. https://clinicaltrialsgov/ct2/show/NCT00629629, accessed April 15, 20212008

21. Ferreira VR, Sangalli CN, Leffa PS, et al. The impact of a primary health care intervention on infant feeding practices: a cluster randomised controlled trial in Brazil. J Hum Nutr Diet 2019;32(1):21-30. doi: 10.1111/jhn.12595

22. ClinicalTrials.gov Registry. Impact of the "Ten Steps for Healthy Feeding of Children Younger Than Two Years" in Health Centers. https://clinicaltrialsgov/ct2/show/NCT00635453, accessed July 26, 20212008

23. Dennis CL, Marini F, Dick JA, et al. Protocol for a randomised trial evaluating a preconception-early childhood telephone-based intervention with tailored e-health resources for women and their partners to optimise growth and development among children in Canada: a Healthy Life Trajectory Initiative (HeLTI Canada). BMJ Open 2021;11(2) doi: 10.1136/bmjopen-2020-046311

24. ISRCTN Registry. Preconception-early childhood telephone-based intervention to optimize growth and development among children in Canada: A Healthy Life Trajectory Initiative (HeLTI-Canada). http://wwwisrctncom/ISRCTN13308752, accessed September 21, 20202019

25. chictr.org.cn Registry. A Multifaceted Community-Family-Mother-Child Intervention Study for the Prevention of Childhood Obesity. http://wwwchictrorgcn/showprojenaspx?proj=30062, accessed September 22, 20202018

26. Chinese Clinical Trials Register. SCHeLTI (Sino-Canadian Healthy Life Trajectory Initiative). http://wwwchictrorgcn/showprojenaspx?proj=30062, accessed July 29, 20202018

27. ClinicalTrials.gov Registry. Effects of Lifestyle Intervention on Childhood Outcomes in LGA Infants. https://clinicaltrialsgov/ct2/show/NCT04661449, accessed on April 15, 20212020

28. Carlsen EM, Kyhnaeb A, Renault KM, et al. Telephone-based support prolongs breastfeeding duration in obese women: a randomized trial. The American journal of clinical nutrition 2013;98(5):1226-32.

29. ClinicalTrials.gov Registry. Minimizing the Risk for Obesity During Infancy by Extensive Advisory Service. https://clinicaltrialsgov/ct2/show/NCT01235663, accessed April 15, 20212010

30. ClinicalTrials.gov Registry. INFANT HEALTH- Promoting Mental Health and Healthy Weight in Infancy Through Sensitive Parenting. https://clinicaltrialsgov/ct2/show/NCT04601779, accessed April 15, 20212020

31. ClinicalTrials.gov Registry. Lifestyle Intervention for Toddlers Pilot Study (LIFT). https://wwwclinicaltrialsgov/ct2/show/study/NCT01204489, accessed on September 21, 20202010

32. Parat S, Nègre V, Baptiste A, et al. Prenatal education of overweight or obese pregnant women to prevent childhood overweight (the ETOIG study): an open-label, randomized controlled trial. International Journal of Obesity 2019;43(2):362-73.

33. ClinicalTrials.gov Registry. Impact of Education During Pregnancy in Overweight Pregnant Women (ETOIG). https://clinicaltrialsgov/ct2/show/NCT00804765, accessed April 15, 20212008 


\section{TOPCH̊̊LD}

34. Acero CG, Martinez S, Pérez-Expósito A, et al. Effect of an innovative behavioural change strategy and small-quantity lipid-based nutrient supplements on stunting and obesity in children in Baja Verapaz, Guatemala: protocol for a randomised control trial. BMJ Open 2020;10(7):e035528. doi: 10.1136/bmjopen-2019-035528

35. ClinicalTrials.gov Registry. SPOON: Sustained Program for Improving Nutrition - Guatemala (SPOON-Guate). https://clinicaltrialsgov/ct2/show/NCT03399617, accessed July 29, 20202018

36. Kumaran K, Krishnaveni GV, Suryanarayana KG, et al. Protocol for a cluster randomised trial evaluating a multifaceted intervention starting preconceptionally-Early Interventions to Support Trajectories for Healthy Life in India (EINSTEIN): a Healthy Life Trajectories Initiative (HeLTI) Study. BMJ open 2021;11(2):e045862.

37. ISRCTN Registry. Interventions in early life and through the lifecourse to prevent non-communicable diseases in later life in India. https://doiorg/101186/ISRCTN20161479, accessed April 15, 20212020

38. Clinical Trials Registry - India. Early Interventions to Support Trajectories for Healthy Life in India. http://wwwctrinicin/Clinicaltrials/pdf generatephp?trialid=48266\&EncHid=\&modid=\&compid=\%27,\%2748266det\%27, accessed April 15, 2021 2020

39. ANZCTR Registry. Bump 2 Baby and Me: A study to test health coaching for healthy eating and activity during pregnancy and the first year after a baby is born. http://wwwanzctrorgau/Trial/Registration/TrialReviewaspx?id=380020\&isReview=true, accessed April 15, 20212020

40. Morandi A, Tommasi M, Soffiati F, et al. Prevention of obesity in toddlers (PROBIT): a randomised clinical trial of responsive feeding promotion from birth to 24 months. International Journal of Obesity 2019;43(10):1961-66.

41. ClinicalTrials.gov Registry. Prevention of Obesity in Toddlers (PROBIT) Trial. https://clinicaltrialsgov/ct2/show/NCT03131284, accessed April 15, 2021 2017

42. De Vries A, Huiting H, Van Den Heuvel E, et al. An activity stimulation programme during a child's first year reduces some indicators of adiposity at the age of two-and-a-half. Acta Paediatrica 2015;104(4):414-21.

43. ClinicalTrials.gov Registry. Early Obesity Intervention Program Within GECKO Drenthe; a Randomized Controlled Trial. https://clinicaltrialsgov/ct2/show/NCT01127412, accessed April 15, 20212010

44. Karssen LT, Vink JM, De Weerth C, et al. An app-based parenting program to promote healthy energy balance $\Downarrow$ related parenting practices to prevent childhood obesity: Protocol using the intervention mapping framework. JMIR Form Res 2021;5(5) doi: 10.2196/24802

45. Netherlands Trial Register. The effectiveness of an mHealth parenting intervention to prevent childhood obesity: A randomized controlled trial. https://wwwtrialregisternl/trial/6727, accessed September 22, 20202017

46. van der Veek S, de Graaf C, de Vries J, et al. Baby's first bites: a randomized controlled trial to assess the effects of vegetable-exposure and sensitive feeding on vegetable acceptance, eating behavior and weight gain in infants and toddlers. BMC pediatrics 2019;19(1):266.

47. ClinicalTrials.gov Registry. Baby's First Bites: Promoting Vegetable Intake in Infants and Toddlers. https://clinicaltrialsgov/ct2/show/NCT03348176, accessed April 15, 20212017

48. Netherlands Trial Register. Baby's first bites. https://wwwtrialregisternl/trial/6397, accessed April 15, 20212017

49. Van Grieken A, Vlasblom E, Wang L, et al. Personalized web-based advice in combination with well-child visits to prevent overweight in young children: cluster randomized controlled trial. Journal of medical Internet research 2017;19(7):e268.

50. Netherlands Trial Register. The BeeBOFT Study. https://wwwtrialregisternl/trial/1721, accessed April 15, 20212009 


\section{TOPCH§̊LD}

51. Raat H, Struijk MK, Remmers T, et al. Primary prevention of overweight in preschool children, the BeeBOFT study (breastfeeding, breakfast daily, outside playing, few sweet drinks, less TV viewing): design of a cluster randomized controlled trial. BMC Public Health 2013;13(1):974.

52. Taylor BJ, Gray AR, Galland BC, et al. Targeting sleep, food, and activity in infants for obesity prevention: an RCT. Pediatrics 2017;139(3):e20162037.

53. ClinicalTrials.gov Registry. Prevention of Overweight in Infancy (POInz). https://clinicaltrialsgov/ct2/show/NCT00892983, accessed April 15, 2021 2009

54. Taylor BJ, Heath A-LM, Galland BC, et al. Prevention of Overweight in Infancy (POI. nz) study: a randomised controlled trial of sleep, food and activity interventions for preventing overweight from birth. BMC Public Health 2011;11(1):1-11.

55. Taylor RW, Williams SM, Fangupo LJ, et al. Effect of a baby-led approach to complementary feeding on infant growth and overweight: a randomized clinical trial. JAMA pediatrics 2017;171(9):838-46.

56. ANZCTR Registry. Baby-led introduction to solids (BLISS). http://wwwanzctrorgau/Trial/Registration/TrialReviewaspx?id=363183\&isReview=true, accessed Aprl 15, 20212012

57. Daniels L, Heath A-LM, Williams SM, et al. Baby-Led Introduction to SolidS (BLISS) study: a randomised controlled trial of a baby-led approach to complementary feeding. BMC pediatrics 2015;15(1):1-15.

58. Helle C, Hillesund ER, Wills AK, et al. Evaluation of an eHealth intervention aiming to promote healthy food habits from infancy-the Norwegian randomized controlled trial Early Food for Future Health. International Journal of Behavioral Nutrition and Physical Activity 2019;16(1):1.

59. ISRCTN Registry. Early Food for Future Health: an E-health intervention aiming to promote healthy food habits from early childhood. https://doiorg/101186/ISRCTN13601567, accessed April 15, 20212016

60. Helle C, Hillesund ER, Omholt ML, et al. Early food for future health: a randomized controlled trial evaluating the effect of an eHealth intervention aiming to promote healthy food habits from early childhood. BMC Public Health 2017;17(1):729.

61. Beinert C, Hernes S, Haugen M, et al. No long-term effect of a 2-days intervention on how to prepare homemade food, on toddlers' skepticism for new food and intake of fruits and vegetables and sweet beverages: a randomized, controlled trial. BMC research notes 2017;10(1):607.

62. ISRCTN Registry. First food for infants. https://doiorg/101186/ISRCTN45864056, accessed April 15, 20212016

63. Røed M, Hillesund ER, Vik FN, et al. The Food4toddlers study-study protocol for a web-based intervention to promote healthy diets for toddlers: a randomized controlled trial. BMC public health 2019;19(1):563.

64. ISRCTN Registry. Fostering healthy dietary habits through a mobile-health intervention targeting toddlers' food and eating environment https://doiorg/101186/ISRCTN92980420, accessed April 15, 20212017

65. Røed M, Medin AC, Vik FN, et al. Effect of a Parent-Focused eHealth Intervention on Children's Fruit, Vegetable, and Discretionary Food Intake (Food4toddlers): Randomized Controlled Trial. Journal of medical Internet research 2021;23(2):e18311.

66. pactr.samrc.ac.za Registry. A preconception cluster randomised controlled trial, part of the Healthy Life Trajectories Initiative (HeLTI). https://pactrsamrcacza/TrialDisplayaspx?TrialID=6015, accessed September 21, 20202019

67. ClinicalTrials.gov Registry. Effectiveness of a Motivational Interviewing-based Intervention From Pregnancy to 2 Years of Age. (PROGESPI). https://clinicaltrialsgov/ct2/show/NCT03444415, accesssed September 23, 20202018

68. Sobko T, Svensson V, Ek A, et al. A randomised controlled trial for overweight and obese parents to prevent childhood obesity-Early STOPP (STockholm Obesity Prevention Program). BMC Public Health 2011;11(1):336.

69. ClinicalTrials.gov Registry. Early Stockholm Obesity Prevention Program (EarlySTOPP). https://clinicaltrialsgov/ct2/show/NCT01198847, accessed April 15, 20212010 


\section{TOPCHY̊LD}

70. Döring N, Ghaderi A, Bohman B, et al. Motivational interviewing to prevent childhood obesity: a cluster RCT. Pediatrics 2016;137(5):e20153104.

71. ISRCTN Registry. PRIMROSE: Primary prevention of childhood obesity at child health centers. https://doiorg/101186/ISRCTN16991919, accessed April 15, 20212013

72. Döring N, Hansson LM, Andersson ES, et al. Primary prevention of childhood obesity through counselling sessions at Swedish child health centres: design, methods and baseline sample characteristics of the PRIMROSE cluster-randomised trial. BMC Public Health 2014;14(1):335.

73. McEachan RR, Santorelli G, Bryant M, et al. The HAPPY (Healthy and Active Parenting Programmme for early Years) feasibility randomised control trial: acceptability and feasibility of an intervention to reduce infant obesity. BMC public health 2016;16(1):1-15.

74. ISRCTN Registry. Healthy and Active Parenting Programme for early Years (HAPPY) - A pilot RCT to evaluate a parenting intervention to prevent childhood obesity in a bi ethnic population. https://doiorg/101186/ISRCTN56735429, accessed April 15, 20212013

75. Bryant $\mathrm{M}$, Collinson $\mathrm{M}$, Burton $\mathrm{W}$, et al. Cluster randomised controlled feasibility study of HENRY: a community-based intervention aimed at reducing obesity rates in preschool children. Pilot and Feasibility Studies 2021;7(1) doi: 10.1186/s40814-021-00798-z

76. ClinicalTrials.gov Registry. Protocol Feasibility Study of HENRY. https://clinicaltrialsgov/ct2/show/NCT03333733, accessed April 15, 2021 2017

77. Bryant $\mathrm{M}$, Burton $\mathrm{W}$, Collinson $\mathrm{M}$, et al. Cluster randomised controlled feasibility study of HENRY: a community-based intervention aimed at reducing obesity rates in preschool children. Pilot and Feasibility Studies 2018;4(1):1-15.

78. Lakshman R, Sharp SJ, Whittle F, et al. Randomised controlled trial of a theory-based behavioural intervention to reduce formula milk intake. Archives of disease in childhood 2018;103(11):1054-60.

79. ISRCTN Registry. Baby Milk Study: establishing a healthy growth trajectory from birth. https://doiorg/101186/ISRCTN20814693, accessed April 15, 2021 2011

80. Lakshman R, Whittle F, Hardeman W, et al. Effectiveness of a behavioural intervention to prevent excessive weight gain during infancy (The Baby Milk Trial): study protocol for a randomised controlled trial. Trials 2015;16(1):442.

81. Rosenstock S, Ingalls A, Foy Cuddy R, et al. Effect of a Home-Visiting Intervention to Reduce Early Childhood Obesity Among Native American Children: A Randomized Clinical Trial. JAMA Pediatrics 2020 doi: 10.1001/jamapediatrics.2020.3557

82. ClinicalTrials.gov Registry. Preventing Early Childhood Obesity, Part 1: Family Spirit Nurture, 3-9 Months. https://clinicaltrialsgov/ct2/show/NCT03101943, accessed April 15, 20212017

83. Ingalls A, Rosenstock S, Cuddy RF, et al. Family Spirit Nurture (FSN)-a randomized controlled trial to prevent early childhood obesity in American Indian populations: trial rationale and study protocol. BMC obesity 2019;6(1):18.

84. ClinicalTrials.gov Registry. Preventing Early Childhood Obesity, Part 2: Family Spirit Nurture, Prenatal - 18 Months. https://clinicaltrialsgov/ct2/show/NCT03334266, accessed April 15, 20212017

85. Beck AL, Fernandez A, Rojina J, et al. Randomized controlled trial of a clinic-based intervention to promote healthy beverage consumption among Latino children. Clinical pediatrics 2017;56(9):838-44.

86. ClinicalTrials.gov Registry. Primary Care Beverage Study. https://clinicaltrialsgov/ct2/show/NCT02257203, accessed September 22, 2020 2014

87. ClinicalTrials.gov Registry. Strong Futures: A Trial of Two Primary Care Based Interventions to Promote Optimal Health in Latino Infants and Toddlers. https://clinicaltrialsgov/ct2/show/NCT03438721, accessed July 29, 20202018

88. Paul IM, Savage JS, Anzman SL, et al. Preventing obesity during infancy: a pilot study. Obesity 2011;19(2):353-61. 


\section{TOPCH§̊LD}

89. ClinicalTrials.gov Registry. The SLeeping and Intake Methods Taught to Infants and Mothers Early in Life (SLIMTIME) Project. https://clinicaltrialsgov/ct2/show/NCT00359242, accessed April 15, 20212006

90. Bonuck K, Avraham SB, Lo Y, et al. Bottle-weaning intervention and toddler overweight. The Journal of pediatrics 2014;164(2):306-12. e2.

91. ClinicalTrials.gov Registry. Feeding Young Children Study: Bottle Weaning Intervention (FYCS). https://clinicaltrialsgov/ct2/show/NCT00756626, accessed April 15, 20212008

92. Schroeder N, Rushovich B, Bartlett E, et al. Early obesity prevention: A randomized trial of a practice-based intervention in 0-24-month infants. Journal of Obesity 2015;2015

93. Campos M, Pomeroy J, Mays MH, et al. Intervention to promote physical activation and improve sleep and response feeding in infants for preventing obesity early in life, the baby-act trial: Rationale and design. Contemporary Clinical Trials 2020;99 doi: 10.1016/j.cct.2020.106185

94. ClinicalTrials.gov Registry. The Baby Act Trial. https://clinicaltrialsgov/ct2/show/NCT03517891, accessed on September 21, 20202018

95. Cloutier M, Wiley J, Kuo CL, et al. Outcomes of an early childhood obesity prevention program in a low-income community: a pilot, randomized trial. Pediatric Obesity 2018;13(11):677-85.

96. ClinicalTrials.gov Registry. Early Childhood Obesity Prevention Program (ECHO). https://clinicaltrialsgov/ct2/show/NCT02052518, accessed April 15, 20212014

97. Cloutier MM, Wiley J, Wang Z, et al. The Early Childhood Obesity Prevention Program (ECHO): an ecologically-based intervention delivered by home visitors for newborns and their mothers. BMC Public Health 2015;15(1):584.

98. de la Haye K, Bell BM, Salvy SJ. The role of maternal social networks on the outcomes of a home-based childhood obesity prevention pilot intervention. J Soc Struct 2019;20(3):7-28. doi: 10.21307/joss-2019-004

99. de la Haye K, Fluke M, Laney PC, et al. In-home obesity prevention in low-income infants through maternal and social transmission. Contemporary clinical trials 2019;77:61-69.

100. ClinicalTrials.gov Registry. In-home Obesity Prevention to Reach Low-income Infants. https://clinicaltrialsgov/ct2/show/NCT03529695, accessed April 15,20212018

101. Fiks A, Gruver R, Bishop-Gilyard C, et al. A social media peer group for mothers to prevent obesity from infancy: the Grow2Gether randomized trial. Childhood Obesity 2017

102. ClinicalTrials.gov Registry. Grow2Gether Pilot Study. https://wwwclinicaltrialsgov/ct2/show/NCT02037490, accessed April 15, 20212014

103. ClinicalTrials.gov Registry. Building Social Networks to Enhance Postpartum Weight Loss and Appropriate Infant Feeding Practices. https://clinicaltrialsgov/ct2/show/NCT01081340, accessed April 15, 20212010

104. ClinicalTrials.gov Registry. Improving the Eating Habits of Mother and Her Infant Via Sugar Reduction (MAMITA). https://wwwclinicaltrialsgov/ct2/show/NCT03141346, accessed September 22, 20202017

105. French GM, Nicholson L, Skybo T, et al. An evaluation of mother-centered anticipatory guidance to reduce obesogenic infant feeding behaviors. Pediatrics 2012;130(3):e507-e17.

106. ClinicalTrials.gov Registry. Anticipatory Guidance to Prevent Childhood Obesity (MOMS). https://clinicaltrialsgov/ct2/show/NCT01565525, accessed April 15, 20212012

107. Groner JA, Skybo T, Murray-Johnson L, et al. Anticipatory guidance for prevention of childhood obesity: design of the MOMS project. Clinical pediatrics 2009;48(5):483-92. 


\section{TOPCHஜ̊LD}

108. ClinicalTrials.gov Registry. Learning to Love Mealtime Together (LiTTLe Me). https://clinicaltrialsgov/ct2/show/NCT04502979, accessed April 15, 2021 2020

109. Horodynski MA, Pierce SJ, Reyes-Gastelum D, et al. Feeding Practices and Infant Growth: Quantifying the Effects of Breastfeeding Termination and Complementary Food Introduction on BMI z-Score Growth Velocity through Growth Curve Models. Childhood Obesity 2017;13(6):490-98.

110. ANZCTR Registry. Infant-Centered Feeding in a low income population. http://wwwanzctrorgau/Trial/Registration/TrialReviewaspx?id=335440\&isReview=true, accessed April 15, 20212010

111. Horodynski MA, Olson B, Baker S, et al. Healthy babies through infant-centered feeding protocol: an intervention targeting early childhood obesity in vulnerable populations. BMC Public Health 2011;11(1):1-6.

112. Horodynski MA, Silk K, Hsieh G, et al. Tools for teen moms to reduce infant obesity: a randomized clinical trial. BMC Public Health 2015;15(1):1-9.

113. ClinicalTrials.gov Registry. Tools For Teen Moms: Reducing Infant Obesity Risk (TFTM). https://clinicaltrialsgov/ct2/show/NCT02244424, accessed April 15, 20212014

114. Trak-Fellermeier MA, Campos M, Meléndez M, et al. PEARLS randomized lifestyle trial in pregnant Hispanic women with overweight/obesity: gestational weight gain and offspring birthweight. Diabetes, Metabolic Syndrome and Obesity: Targets and Therapy 2019;12:225.

115. ClinicalTrials.gov Registry. Pregnancy and EARly Lifestyle Improvement Study (PEARLS). https://clinicaltrialsgov/ct2/show/NCT01771133, accessed April 15,20212013

116. Karasz A, Bonuck K. Reducing pediatric caries and obesity risk in South Asian immigrants: randomized controlled trial of common health/risk factor approach. BMC public health 2018;18(1):680.

117. ClinicalTrials.gov Registry. Obesity and Caries in Young South Asian Children: A Common Risk Factor Approach (CHALO). https://clinicaltrialsgov/ct2/show/NCT03077425, accessed on July 31, 20202017

118. Lavner JA, Stansfield BK, Beach SR, et al. Sleep SAAF: a responsive parenting intervention to prevent excessive weight gain and obesity among African American infants. BMC pediatrics 2019;19(1):224.

119. ClinicalTrials.gov Registry. Sleep-Safe: A Strong African American Families Study. https://clinicaltrialsgov/ct2/show/NCT03505203, accessed April 15, 20212018

120. Linares AM, Cartagena D, Rayens MK. Las Dos Cosas versus exclusive breastfeeding: a culturally and linguistically exploratory intervention study in Hispanic mothers living in Kentucky. Journal of Pediatric Health Care 2019;33(6):e46-e56.

121. ClinicalTrials.gov Registry. Childhood Risk Reduction Program in Hispanics (ECOR-H). https://clinicaltrialsgov/ct2/show/NCT03903146, accessed April 15, 20212019

122. Gross RS, Mendelsohn AL, Gross MB, et al. Randomized controlled trial of a primary care-based child obesity prevention intervention on infant feeding practices. The Journal of pediatrics 2016;174:171-77. e2.

123. ClinicalTrials.gov Registry. Starting Early Obesity Prevention Program. https://clinicaltrialsgov/ct2/show/NCT01541761, accessed April 15, 20212012

124. Palacios C, Campos M, Gibby C, et al. Effect of a multi-site trial using short message service (SMS) on infant feeding practices and weight gain in lowincome minorities. Journal of the American College of Nutrition 2018;37(7):605-13.

125. Registry Cg. Multi-site Trial Using SMS to Improve Infant Weight (SMS). https://clinicaltrialsgov/ct2/show/NCT02903186, accessed April 15, 2021 2016

126. Banna J, Campos M, Gibby C, et al. Multi-site trial using short mobile messages (SMS) to improve infant weight in low-income minorities: Development, implementation, lessons learned and future applications. Contemporary Clinical Trials 2017;62:56-60. doi: 10.1016/j.cct.2017.08.011 


\section{TOPCH̊̊LD}

127. ClinicalTrials.gov Registry. Healthy Sleeping and Feeding During Infancy. https://clinicaltrialsgov/ct2/show/study/NCT00125580, accessed September 21, 20202005

128. Paul IM, Savage JS, Anzman-Frasca S, et al. Effect of a responsive parenting educational intervention on childhood weight outcomes at 3 years of age: The INSIGHT randomized clinical trial. JAMA - Journal of the American Medical Association 2018;320(5):461-68. doi: 10.1001/jama.2018.9432

129. ClinicalTrials.gov Registry. The Intervention Nurses Start Infants Growing on Healthy Trajectories (INSIGHT) Study (INSIGHT). https://clinicaltrialsgov/ct2/show/NCT01167270, accessed April 15, 20212010

130. ClinicalTrials.gov Registry. Intervention Nurses Start Infants Growing on Healthy Trajectories (INSIGHT) - Long Term Follow-Up (INSIGHT). https://clinicaltrialsgov/ct2/show/NCT03555331, accessed April 15, 20212018

131. Paul IM, Williams IS, Anzman-Frasca S, et al. The intervention nurses start infants growing on healthy trajectories (INSIGHT) study. BMC pediatrics 2014:14(1):1-15

132. Reifsnider E, McCormick DP, Cullen KW, et al. Randomized controlled trial to prevent infant overweight in a high-risk population. Academic pediatrics 2018;18(3):324-33.

133. ClinicalTrials.gov Registry. Preventing Childhood Obesity Through Early Guidance. https://clinicaltrialsgov/ct2/show/NCT01905072, accessed April 15, 20212013

134. Reifsnider E, McCormick DP, Cullen KW, et al. A randomized controlled trial to prevent childhood obesity through early childhood feeding and parenting guidance: rationale and design of study. BMC Public Health 2013;13(1):880.

135. Sanders LM, Perrin EM, Yin HS, et al. A health-literacy intervention for early childhood obesity prevention: A cluster-randomized controlled trial. Pediatrics 2021;147(5) doi: 10.1542/peds.2020-049866

136. Sanders LM, Perrin EM, Yin HS, et al. “Greenlight study”: a controlled trial of low-literacy, early childhood obesity prevention. Pediatrics 2014;133(6):e1724-e37.

137. Salvy S-J, Dutton GR, Borgatti A, et al. Habit formation intervention to prevent obesity in low-income preschoolers and their mothers: A randomized controlled trial protocol. Contemporary clinical trials 2018;70:88-98.

138. ClinicalTrials.gov Registry. Healthy Homes, Healthy Habits (HABITS). https://clinicaltrialsgov/ct2/show/NCT03433456, accessed April 15, 2021 2018

139. Savage JS, Kling SM, Cook A, et al. A patient-centered, coordinated care approach delivered by community and pediatric primary care providers to promote responsive parenting: pragmatic randomized clinical trial rationale and protocol. BMC pediatrics 2018;18(1):1-11.

140. ClinicalTrials.gov Registry. Coordination of Care Between Pediatricians and Women Infants \& Children Nutritionists (WEE). https://clinicaltrialsgov/ct2/show/NCT03482908, accessed April 15, 20212018

141. Spieker EA, Sbrocco T, Theim KR, et al. Preventing Obesity in the Military Community (POMC): the development of a clinical trials research network. International journal of environmental research and public health 2015;12(2):1174-95.

142. ClinicalTrials.gov Registry. Preventing Obesity in Military Communities: Mother-Baby. https://clinicaltrialsgov/ct2/show/NCT03249324, accessed April 15, 20212017

143. ClinicalTrials.gov Registry. Healthy Start to Feeding Intervention. https://clinicaltrialsgov/ct2/show/study/NCT03597061, accessed on September 21, 20202018

144. Whooten RC, Kwete GM, Farrar-Muir H, et al. Engaging fathers in the first 1000 days to improve perinatal outcomes and prevent obesity: Rationale and design of the First Heroes randomized trial. Contemporary Clinical Trials 2021;101 doi: 10.1016/j.cct.2020.106253 


\section{TOPCHํD}

145. ClinicalTrials.gov Registry. First Heroes: Engaging Fathers in the First 1000 Days (First Heroes). https://clinicaltrialsgov/ct2/show/NCT04477577, accessed April 15, 20212020

146. ClinicalTrials.gov Registry. Back to Basics: Addressing Childhood Obesity Through Traditional Foods in Alaska. https://clinicaltrialsgov/ct2/show/NCT03601299, accessed on September 16, 20202018

147. Thomson J, Goodman M, Tussing-Humphreys L, et al. Infant growth outcomes from birth to 12 months of age: findings from the Delta Healthy Sprouts randomized comparative impact trial. Obesity science \& practice 2018;4(4):299-307.

148. ClinicalTrials.gov Registry. Delta Healthy Sprouts: Intervention to Promote Maternal Weight Control and Reduce Childhood Obesity in the MS Delta. https://clinicaltrialsgov/ct2/show/NCT01746394, accessed April 15, 20212012

149. Thomson JL, Tussing-Humphreys LM, Goodman MH. Delta healthy sprouts: a randomized comparative effectiveness trial to promote maternal weight control and reduce childhood obesity in the Mississippi Delta. Contemporary clinical trials 2014;38(1):82-91.

150. ClinicalTrials.gov Registry. Peer-mentored Cooking Classes for Parents of Toddlers: Do Families Cook More and Eat Healthier After the Intervention? https://clinicaltrialsgov/ct2/show/NCT01710423, accessed on September 17, 20202012

151. Wasser HM, Thompson AL, Suchindran CM, et al. Home-based intervention for non-Hispanic black families finds no significant difference in infant size or growth: results from the Mothers \& Others randomized controlled trial. BMC pediatrics 2020;20(1):1-13.

152. ClinicalTrials.gov Registry. Mothers and Others: Family-based Obesity Prevention for Infants and Toddlers. https://clinicaltrialsgov/ct2/show/NCT01938118, accessed April 15, 20212013

153. Wasser HM, Thompson AL, Suchindran CM, et al. Family-based obesity prevention for infants: Design of the "Mothers \& Others" randomized trial. Contemporary clinical trials 2017;60:24-33.

154. ClinicalTrials.gov Registry. Mothers And careGivers Investing in Children (MAGIC). https://clinicaltrialsgov/ct2/show/NCT04177472, accessed September 22, 20202019 